\title{
A label-free differential quantitative mass spectrometry method for the characterization and identification of protein changes during citrus fruit development
}

\author{
Ehud Katz', Mario Fon ${ }^{1}$, Richard A Eigenheer ${ }^{2}$, Brett S Phinney², Joseph N Fass ${ }^{3}$, Dawei Lin ${ }^{3}$, Avi Sadka ${ }^{4}$, \\ Eduardo Blumwald ${ }^{1 *}$
}

\begin{abstract}
Background: Citrus is one of the most important and widely grown commodity fruit crops. In this study a labelfree LC-MS/MS based shot-gun proteomics approach was taken to explore three main stages of citrus fruit development. These approaches were used to identify and evaluate changes occurring in juice sac cells in various metabolic pathways affecting citrus fruit development and quality.

Results: Protein changes in citrus juice sac cells were identified and quantified using label-free shotgun methodologies. Two alternative methods, differential mass-spectrometry (dMS) and spectral counting (SC) were used to analyze protein changes occurring during earlier and late stages of fruit development. Both methods were compared in order to develop a proteomics workflow that could be used in a non-model plant lacking a sequenced genome. In order to resolve the bioinformatics limitations of EST databases from species that lack a full sequenced genome, we established iCitrus. iCitrus is a comprehensive sequence database created by merging three major sources of sequences (HarvEST:citrus, NCBI/citrus/unigenes, NCBI/citrus/proteins) and improving the annotation of existing unigenes. iCitrus provided a useful bioinformatics tool for the high-throughput identification of citrus proteins. We have identified approximately 1500 citrus proteins expressed in fruit juice sac cells and quantified the changes of their expression during fruit development. Our results showed that both dMS and SC provided significant information on protein changes, with dMS providing a higher accuracy.
\end{abstract}

Conclusion: Our data supports the notion of the complementary use of dMS and SC for label-free comparative proteomics, broadening the identification spectrum and strengthening the identification of trends in protein expression changes during the particular processes being compared.

\section{Background}

Fruit ripening and development has being studied using transcriptomic, proteomics, and metabolomics approaches [1-8]. Quantitative proteomics provides an alternative approach for studies of fruit development. In the last few years, quantitative proteomics has been widely applied for the quantification of complex biological samples [9-11]. The most commonly used approach for comparative proteomic analysis of plant tissues is the application of

\footnotetext{
* Correspondence: eblumwald@ucdavis.edu

'Department of Plant Sciences, University of California, Davis, CA, 95616, USA Full list of author information is available at the end of the article
}

2DE-gels. This method is limited in sensitivity, has a low dynamic range, it is inefficient when analyzing insoluble proteins or proteins with very high or low molecular mass and are limited in their reproducibility [12], although reproducibility has been improved with the use of differential imaging gel electrophoresis (DIGE) [13,14]. Alternative techniques to 2DE-gels are non-gel LC-MS/MS-based shotgun proteomics [15-18], where quantification is performed using the mass-spectrometer data. Some success for the quantification of proteins has been achieved by using stable isotope labeling, ${ }^{15} \mathrm{~N},{ }^{13} \mathrm{C},{ }^{2} \mathrm{H}$ and SILAC [19], ICAT [20,21], iTRAQ [22] and ${ }^{18} \mathrm{O}$ stable isotope incorporation [23]. One of the main limitations of these

()

(c) 2010 Katz et al; licensee BioMed Central Ltd. This is an Open Access article distributed under the terms of the Creative Commons Attribution License (http://creativecommons.org/licenses/by/2.0), which permits unrestricted use, distribution, and reproduction in any medium, provided the original work is properly cited. 
methods is that full labeling of the proteins is rarely achieved and that different peptides incorporate the label at different rates which complicates data analysis. Recently, a label-free method for comparative proteomic analysis has emerged [9-11,24].

Label-free proteomics allows for the quantification of peptides using spectral characteristics such as retention time, $\mathrm{m} / \mathrm{z}$ ratio and peak intensity by comparing the direct mass spectrometric signal intensity for any given peptide (differential Mass Spectrometry, dMS) or by counting the number of acquired tandem mass spectra matching to a specific peptide as an indicator for their abundance in a given sample (spectral counting, SC) $[25,26]$. dMS is based on comparisons of chromatographic peaks of peptide precursor ion measurements belonging to a specific protein extracted from an LCMS/MS run [27-32]. This approach is based on the observation that dMS in most cases is proportional to the concentration of the peptide in the sample investigated [10,27-29]. Peak intensity for every individual spectrum is determined and the comparison of spectra between multiple LC-MS runs provides quantitative measurement of thousands of peptides. From this massive data a selected list of differential peptides can be produced for subsequent fragmentation by LC-MS/MS for sequence determination and protein identification. In order to match the massive spectra data according to retention time and precursor $\mathrm{m} / \mathrm{z}$ characteristics various software have been developed. Once matched, expression ratio in peak intensity is calculated according to peak areas corresponding to the matched peptides. SC counting is based on counting and comparing the number of spectra identifying specific peptides of a given protein to assess relative protein abundance, also found to be in good correlation with protein abundance $[15,30]$.

Proteomics has been used successfully to characterize and identify changes in plant protein compositions during different developmental stages $[3,5,33,34]$, and proteomic comparative analysis of citrus fruits, mainly using 2DE-gels, have been published recently [35-38].

Label-free comparative proteomics is a relatively new approach that has been used successfully in different systems (humans, yeast, fly, etc.) [39-42], but its application in plants is scanty $[26,43]$. Using LC-MS/MS we recently analyzed soluble and enriced membrane fractions of mature citrus fruit to identity the proteome of fruit juice cells and classified these proteins according to their putative function according to known biosynthetic pathways [18]. Here, we describe a method for the use of label-free LC-MS/MS-based shotgun differential proteomics for the study of fruit development in Citrus, a non-model plant lacking a fully sequenced genome. The method combines the use of dMS and SC and the creation of iCitrus, a citrus fruit-specific database and interface, for the identification of the protein changes occurring during the development of citrus fruits.

\section{Results}

\section{Citrus proteins annotations using iCitrus}

Although the citrus genome has not been fully sequenced yet, a comprehensive citrus EST database has been developed in the past few years [44]. Several groups have contributed to EST sequencing efforts using different species, including C. sinensis (sweet orange), C. clementina (Clementine mandarin), C. paradisi (grapefruit), Poncirus trifoliata, and other hybrids $(C$. sinensis $\times$ Poncirus trifoliata, Carrizo citrange). A wide range of libraries derived from multiple reproductive and vegetative tissues at different developmental stages were used in addition to different treatments or stresses to create a relatively large database. To date, there are 582,334 citrus sequences in the National Center for Biotechnology Information (NCBI) EST database. With the advantage of comprehensive sequence dataset in hand, there were many challenges to be addressed before using the databases for proteomic research. Some of these challenges arose from the nature of EST databases, over-representation of highly-expressed genes (and the underrepresentation of weakly-expressed genes), redundancy, incomplete sequences, poor annotation etc. The challenge of using the EST database for proteomics came from the fact that a highly redundant database with many similar sequences would artificially decrease the significance of potential "hits". On the other hand, a strong reduction in sequence-based redundancy, relying on sequence similarity rather than identity, would significantly reduce the number of possible hits. To solve some of these problems, iCitrus http://citrus.bioinformatics.ucdavis.edu/ was created (Figure 1). The iCitrus collected dataset was produced by excluding sequences shorter than 50 amino acids between stop codons and removing redundant sequences with $100 \%$ identity to another longer sequence in the dataset. Similar sequences, sharing less than 100\% similarity were kept for spectra search. Keeping sequences sharing high similarity (97-99\% identify) was a necessity because the citrus ESTs database consists of sequences originated from a wide range of citrus cultivars and species. Minor differences in nucleotide sequences between similar ESTs could lead to differences in amino acid sequences and therefore to differences in virtual spectra derived from the database during mass-spectra search. Keeping these sequences served to broaden our chances of identifying proteins in the databases while discarding them could lead to miss-identification or no identification of proteins. A disadvantage of this approach was the redundancy of accessions that were dealt with by manually aligning the sequences of the 


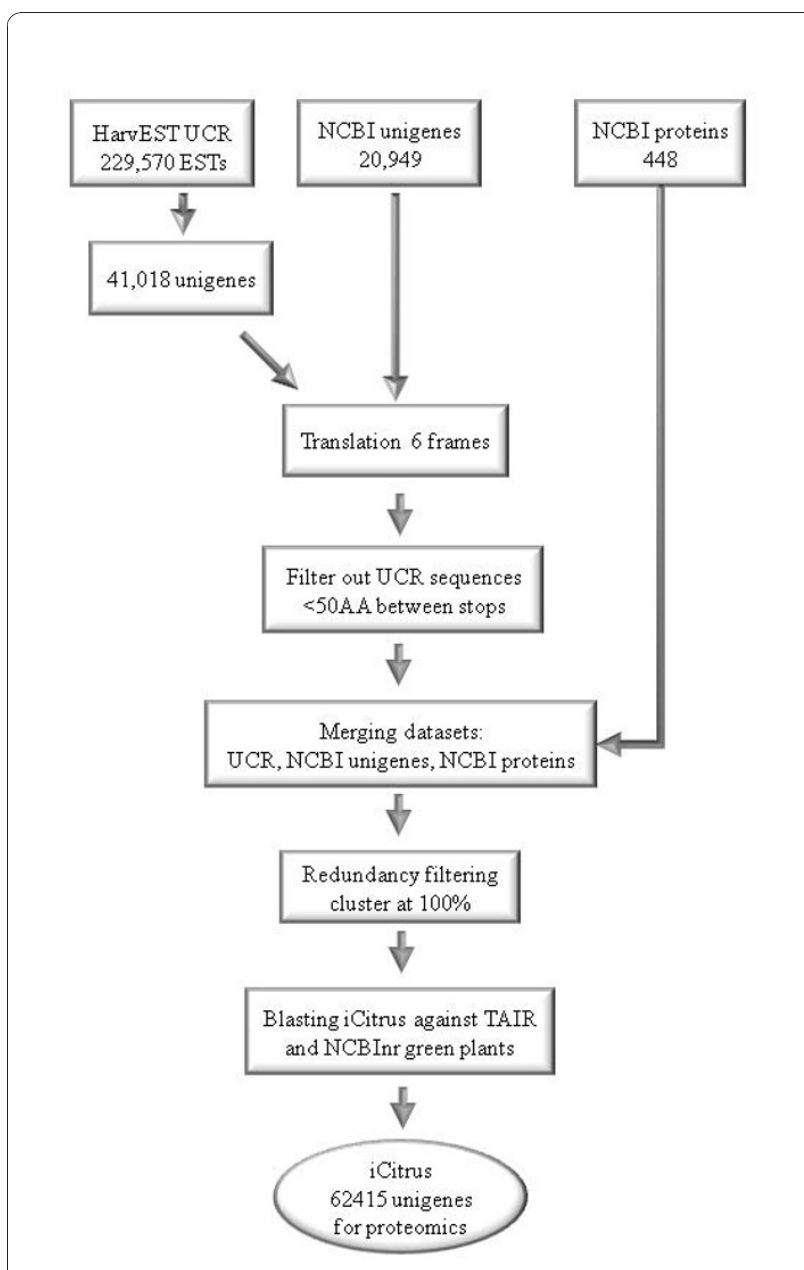

Figure 1 iCitrus database. Three major sources were used in creating iCitrus dataset: UC Riverside HarvEST:citrus (C46 assembly), $\mathrm{NCBI}$ /citrus/unigenes and NCBI/citrus/proteins (see text). The first two datasets were translated into all 6 reading frames, split at stop codons, and sequences shorter than 50 amino acids were removed. These were combined with the NCBI protein sequences, and all three protein sequence sets were then clustered at 100\% identity using CD-HIT http://bioinformatics.ljcrf.edu/cd-hi/, meaning that sequences that aligned with $100 \%$ identity to a longer sequence in the combined set were removed. All remaining sequences were then blasted to TAIR proteins, and separately to the subset of NCBI's $\mathrm{nr}$ database belonging to taxa within Viridiplantae, to collect GOterm and descriptive annotation for the clustered sequences.

proteins of interest. In a few cases where the accessions shared a high similarity, the redundancy resulted in the identification of two or more ESTs with only one peptide. If these ESTs belong to the same unigene, then two or more peptides could identify the same specific protein.

To date, there are 62,415 sequences in the iCitrus collected database; 41,018 from the HarvEST:Citrus assembly http://harvest.ucr.edu/, 20,949 from NCBI's unigenes (C. sinensis and C. clementina), and 448 from NCBI's proteins (C. sinensis and C. clementina) (Figure
1). iCitrus dataset in a FASTA file format and a description of the iCitrus interface structure can be found as Additional File 1 and a conversion table of HarvEST:Citrus, NCBI/Citrus/ESTs and NCBI/Citrus/ Proteins accessions into iCitrus accessions can be found in Additional File 2: Table S1.

\section{Label-free LC-MS/MS based shotgun proteomics, differential Mass-Spec and Spectral Counting}

To achieve a better identification of differentially expressed proteins during fruit development and to decrease sample complexity, the juice sac cells were fractionated into soluble and membrane-bound proteins (Figure 2). Two alternative strategies for label-free mass spectrometric analysis; peptide ion intensities measurements and spectral counting were used. The peptide ion intensities measurements, also referred as differential Mass Spec (dMS), integrate the peak area which is proportional to the concentration of the peptide in the sample (Additional File 3: Figure S1). Determining the area for each mass extracted peptide ion chromatogram

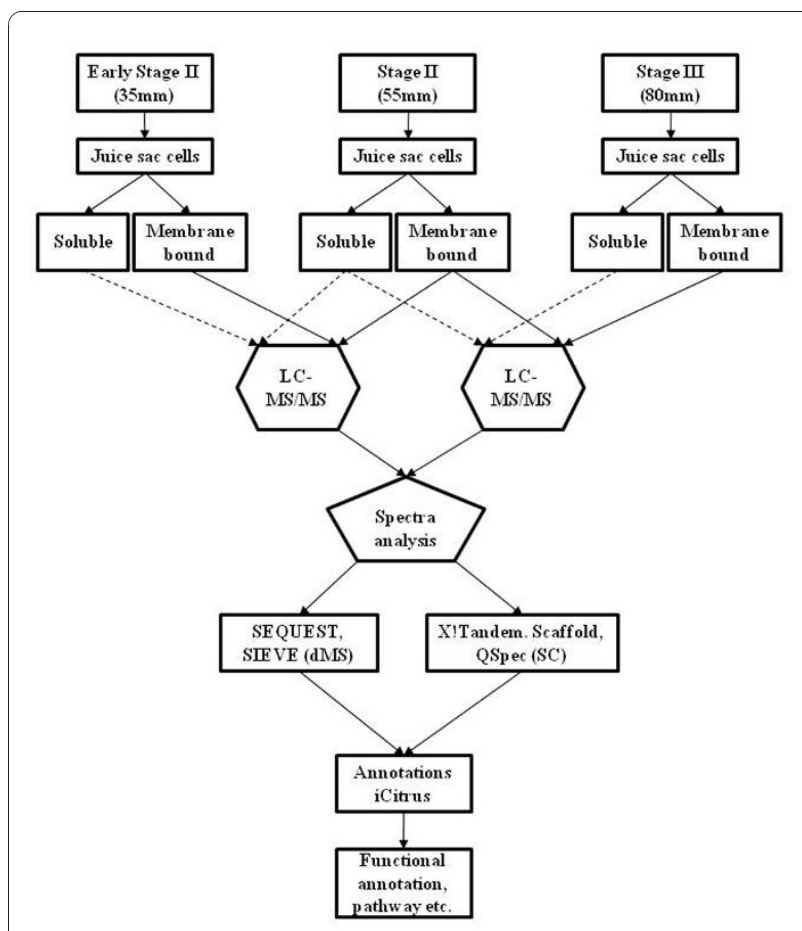

Figure 2 Experimental design. Soluble and membrane-bound proteins were extracted from juice sac cells from at least 20 fruits at three stages of Citrus fruit development (early Stage II, Stage II and Stage III) and pooled at each stage. Five technical repeats of each pooled sample (older vs younger fruit) were each analyzed by SIEVE using blanks (washes) between each sample run. Comparisons were conducted in pairs in the following: Stage II vs. early Stage II and stage III vs. Stage II. Methods as described in Experimental Procedures. 
retention time pair and comparing the areas between multiple LC-MS runs of different samples can provide a comprehensive quantification of thousands of peptides within samples. The alternative strategy, Spectral Counting (SC), calculates the number of MS/MS scans that are attributed to the same peptide ion. The frequency of these MS/MS scans correlates with the abundance of a given peptide in the sample. In this study we have used dMS strategy to analyze and identify differential proteins changes during fruit development in citrus juice sac cells (Figure 2) and SC as an alternative strategy to validate our finding. Identification of proteins was done by MS spectra search against the iCitrus database and annotations by using the iCitrus interface.

Label-free relative quantitative analysis detects, selects and compares spectra that are significantly different between samples (either by dMS or SC). However, many of the spectra that were selected as being different in their intensity or abundance were found to be not statistically different between the developmental stages compared and will be discussed later.

Using dMS, 1494 and 1364 proteins were identified by at least two peptides in the comparisons between Stage II (55 mm fruit diameter) versus early Stage II (35 $\mathrm{mm}$ fruit diameter) and Stage III (80 $\mathrm{mm}$ fruit diameter) versus Stage II, respectively (Figure 3). A high number of identified proteins were down- and up-regulated during the earlier and later stages of development, respectively (Figure 3a).

Accessions identified by SC and dMS were compared using both iCitrus and Arabidopsis homologs (Figure 4).

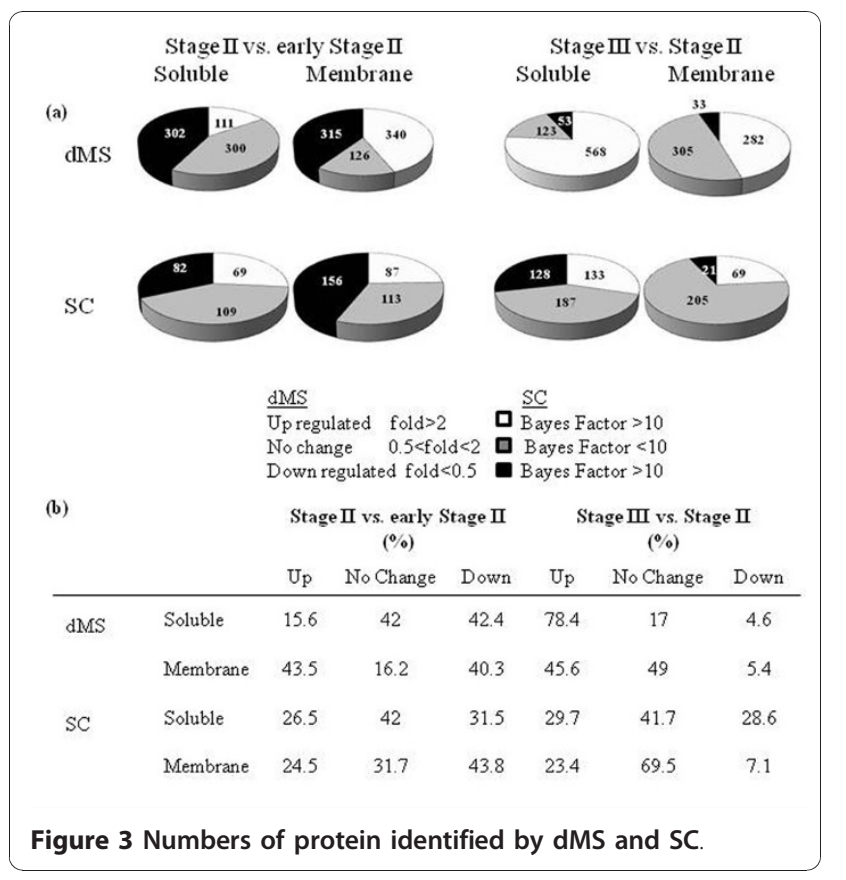

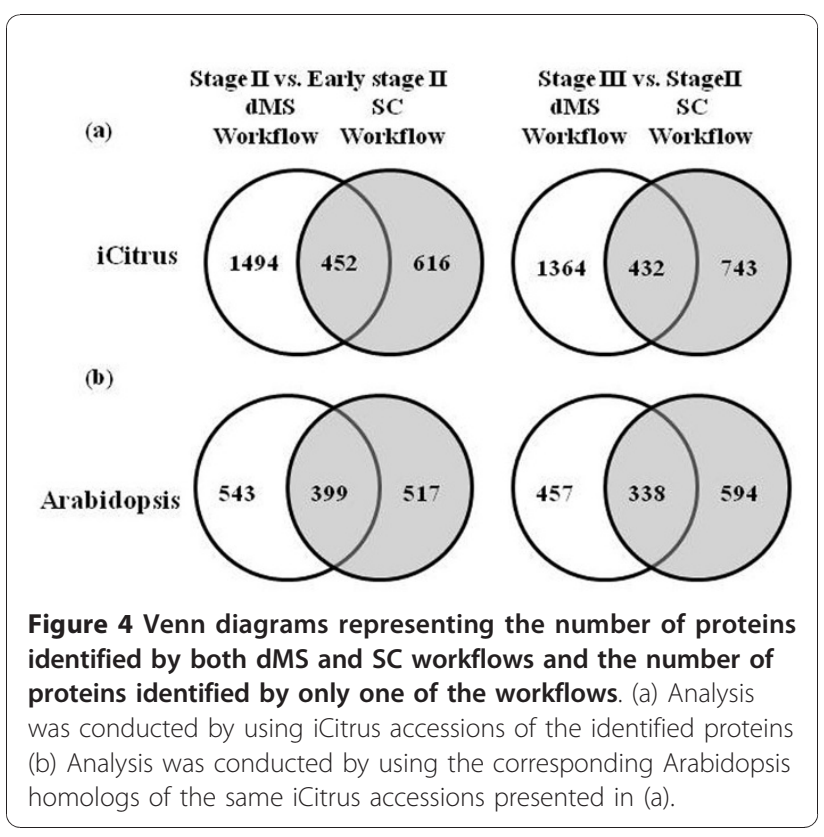

These comparisons were made to minimize possible redundancies of identified citrus ESTs and to conserved citrus protein accessions that might originate from different unigenes but belonging to the same gene family. Once again, aconitase can provide a good example for database redundancy as the accessions 45840 and 47264, sharing 99\% amino acid similarity, are essentially the same unigene originating from two different citrus species (Table 1). These accessions shared little similarity with 39802 and sequence alignment showed that their sequences did not overlap but shared high homology with the other members, i.e. 55395 and 43680. Notably, some proteins did not share homology to any Arabidopsis proteins, providing support to the use of citrus accessions for comparisons. In some cases, these accessions could be assembled to one contig while in other cases these ESTs could not be assembled. Two possibilities arose, either these EST sequences originated from the same gene but did not overlap, therefore could not be assembled, or these ESTs were originated from different genes belonging to the same family.

Most of the proteins identified by both dMS and SC also showed similar expression patterns (Figure 5). Out of 452 proteins identified by both methods in the comparison between fruits at Stage II versus fruits at early Stage II, 308 proteins (69\%) had the same expression pattern therefore referred as "matching" (Figure 5a). In the comparison between fruits at Stage III versus Stage II $51 \%$ of the shared proteins displayed similar expression pattern and the rest fell under the "weak matching" category (Figure 5a). "Weak matching" refers to proteins showing significant expression changes with one method 
Table 1 Identification and quantification of aconitase by dMS and SC.

\begin{tabular}{|c|c|c|c|c|c|c|c|c|c|c|c|c|c|c|c|c|}
\hline \multirow{2}{*}{$\begin{array}{c}\text { dMS } \\
\text { HarvEST } \\
\text { Citrus ID }\end{array}$} & \multirow[b]{2}{*}{ iCitrus ID } & \multirow[b]{2}{*}{$\begin{array}{l}\text { Blast Hit to } \\
\text { TAIR ID }\end{array}$} & \multicolumn{4}{|c|}{ Stage II vs. early Stage II } & \multirow[b]{2}{*}{ Ratio } & \multicolumn{2}{|c|}{ Stage III vs. Stage II } & \multirow[b]{2}{*}{$\begin{array}{l}\text { Max. } \\
\text { Xcorr }\end{array}$} & & & & & & \\
\hline & & & Ratio & Pvalue & $\begin{array}{c}\text { No. } \\
\text { peptides }\end{array}$ & $\begin{array}{l}\text { Max. } \\
\text { Xcorr }\end{array}$ & & Pvalue & $\begin{array}{c}\text { No. } \\
\text { peptides }\end{array}$ & & & & & & & \\
\hline UC46_7402 & 39802 & AT2G05710 & 24.9 & $9.9 \mathrm{E}-20$ & 3 & 5.39 & 33.6 & $3.621 \mathrm{E}-07$ & 4 & 4.56 & & & & & & \\
\hline UC46_5405 & 43680 & AT2G05710 & 25.3 & $9.9 \mathrm{E}-20$ & 2 & 5.39 & 13.6 & $9.9 \mathrm{E}-20$ & 2 & 4.56 & & & & & & \\
\hline UC46_5554 & 47264 & AT2G05710 & 62.0 & $9.9 \mathrm{E}-20$ & 2 & 5.40 & 4.9 & 0.0007414 & 3 & 6.52 & & & & & & \\
\hline UC46_5555 & 45840 & AT2G05710 & 49.7 & $9.9 \mathrm{E}-20$ & 4 & 5.40 & 4.8 & 0.0014824 & 4 & 6.52 & & & & & & \\
\hline UC46_9228 & 55395 & AT2G05710 & 25.3 & $9.9 \mathrm{E}-20$ & 2 & 5.39 & 9.4 & 4.115E-06 & 3 & 5.07 & & & & & & \\
\hline \multicolumn{3}{|c|}{ Spectral Counting } & \multicolumn{7}{|c|}{ Stage II vs. early Stage II } & \multicolumn{7}{|c|}{ Stage III vs. Stage II } \\
\hline $\begin{array}{l}\text { HarvEST } \\
\text { Citrus ID }\end{array}$ & iCitrus ID & $\begin{array}{l}\text { Blast Hit to } \\
\text { TAIR ID }\end{array}$ & $\begin{array}{l}\text { Bayes } \\
\text { Factor }\end{array}$ & $\begin{array}{l}\text { Fold } \\
\text { Change }\end{array}$ & Direction & $\begin{array}{c}\text { No. } \\
\text { peptides }\end{array}$ & $-\log (e)$ & $\begin{array}{l}\text { FDR } \\
\text { Down }\end{array}$ & $\begin{array}{l}\text { FDR } \\
\text { up }\end{array}$ & $\begin{array}{l}\text { Bayes } \\
\text { Factor }\end{array}$ & $\begin{array}{l}\text { Fold } \\
\text { Change }\end{array}$ & Direction & $\begin{array}{c}\text { No. } \\
\text { peptides }\end{array}$ & $\begin{array}{l}-\log \\
\text { (e) }\end{array}$ & $\begin{array}{l}\text { FDR } \\
\text { Down }\end{array}$ & $\begin{array}{l}\text { FDR } \\
\text { up }\end{array}$ \\
\hline UC46_7402 & 39802 & AT2G05710 & 0.66 & 1.88 & 0 & 4 & 9.3 & 1.26 & 0.91 & 30.46 & 5.52 & 1 & 3 & 4.6 & 0.80 & 0.00 \\
\hline UC46_5405 & 43680 & AT2G05710 & - & - & - & - & - & - & - & 143.42 & 12.24 & 1 & 2 & 3.7 & 1.03 & 0.88 \\
\hline UC46_5555 & 45840 & AT2G05710 & 0.4 & 1.08 & 0 & 3 & 14.9 & 1.20 & 0.91 & 0.58 & 1.29 & 0 & 4 & 13.0 & 0.89 & 0.75 \\
\hline \multirow[t]{2}{*}{ UC46_9228 } & 55395 & AT2G05710 & 0.42 & 1.08 & 0 & 2 & 11.7 & 1.26 & 0.91 & 0.68 & 1.11 & 0 & 3 & 11.0 & 0.73 & 0.86 \\
\hline & HarvEST & & UC46_7402 & UC46_5405 & UC46_5555 & UC46_5554 & UC46_9228 & & & & & & & & & \\
\hline Origin & Citrus ID & iCitrus ID & 39802 & 43680 & 45840 & 47264 & 55395 & & & & & & & & & \\
\hline C. Sinensis & UC46_7402 & 39802 & & 87 & 17 & 18 & 86 & & & & & & & & & \\
\hline C. Sinensis & UC46_5405 & 43680 & & & 87 & 86 & 86 & & & & & & & & & \\
\hline C. Sinensis & UC46_5555 & 45840 & & & & 99 & 90 & & & & & & & & & \\
\hline P. Trifoliata & UC46_5554 & 47264 & & & & & 89 & & & & & & & & & \\
\hline C. Sinensis & UC46_9228 & 55395 & & & & & & & & & & & & & & \\
\hline
\end{tabular}

All iCitrus accessions for aconitase that were identified by both methods were homolog to the Arabidopsis gene At2g05710. Identification of aconitase by dMS and SC. The column "direction" under SC represents up-regulated $=1$, no change $=0$, down-regulated $=-1$. Aconitase iCitrus accessions amino acids sequences similarities. 
(a)

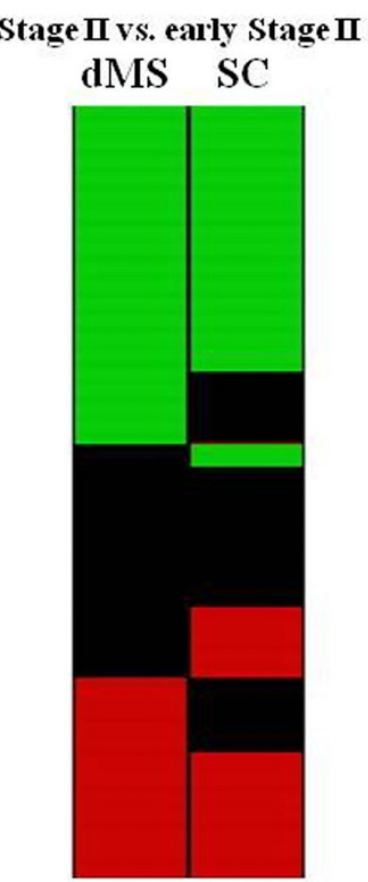

(b)

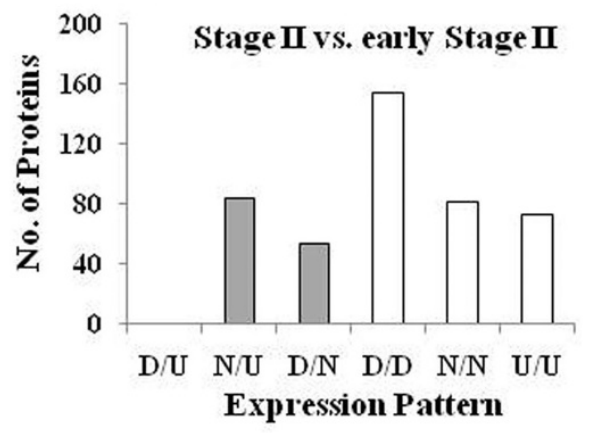

(d)

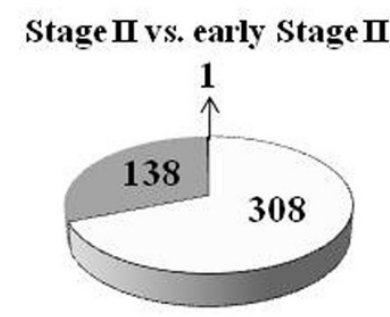

Stage III vs. Stage II

dMS SC

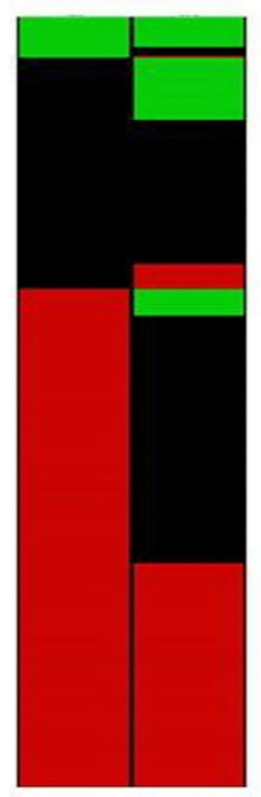

(c)

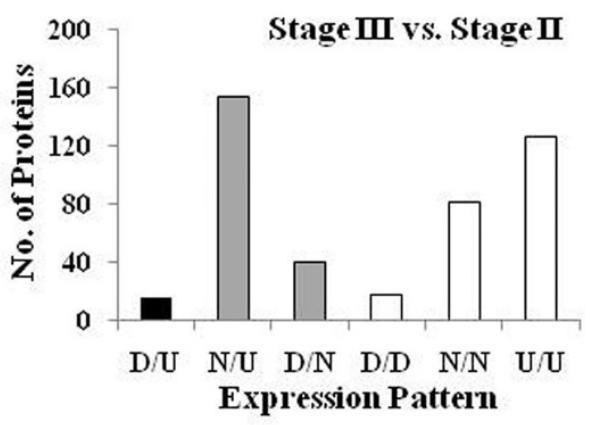

Stage III vs. Stage II

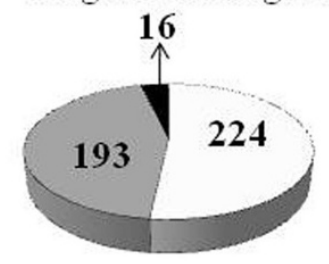

Figure 5 Comparisons of expression trends of proteins identified by dMS and SC. (a). Up-regulated (1-red), unchanged (0-black), downregulated (-1-green). (b-c) Proteins showing the same trend in dMS and SC (strong-match), contradicting trends (no-match) and "weak-match" for proteins identified by one of the methods as not changing. D-down-regulated, N-no change, U-up-regulated. Strong expression "match", (U/ U, D/D, N/N according to dMS/SC) (white columns); "weak-match", (N/U, U/N, D/N, N/D by dMS/SC) (grey columns); "no-match", (D/U, U/D) (black columns); (b) Stage II vs. early Stage II (c) Stage III vs. Stage II. (d) Proteins identified by dMS and SC that have the same expression trend ("match", white), contradicting expression trend ("no-match", black) and proteins up-regulated or down-regulated in one method but unchanged in the other ("weak-match", grey). 
while showed no significant expression differences when analyzed with the other method (Figure 5b-d). Only few proteins, 1 and 16, showed contradicting expression patterns in the comparisons between Stage II versus early Stage II and between Stage III and Stage II, respectively. The high percentage of proteins shared by dMS and SC that show the same expression pattern serves also as a strong validation for protein expression.

\section{Changes in protein expression during fruit development}

Label-free LC-MS/MS analysis of juice sac cells indicated significant changes in protein synthesis during fruit development (Table 2). Changes in the expression of 1834 and 1004 iCitrus accessions during fruit development were identified by dMS and SC, respectively. These numbers consisted of accessions identified by the four types of comparisons conducted (Stage II vs. early Stage II, Stage III vs. Stage II, membrane-bound proteins and soluble), and proteins appearing at more than one stage of development were only counted once. In most cases, the discrepancies between the two methods were due to differences on the bioinformatics associated with dMS and SC workflows (see Discussion).

A significant number of proteins (772 and 560) were identified and classified as "not changed" by dMS and $\mathrm{SC}$, respectively (Table 2). Although these proteins were found to match differentially expressed peptides, did not pass the statistical threshold. Although not differentially expressed, the identification of these proteins provides valuable information because: (i) they are proteins that are active during fruit development; (ii) they strengthen the confidence in the identification of the same peptides in other comparisons [39]. Here, we have classified the fruit proteins into 14 major functional groups (Table 2). In general, the expression of a large number of proteins identified decreased during the transition from early Stage II to Stage II of development (617 were downregulated and 451 were up-regulated). This trend reversed during the transition from Stage II to Stage III where 850 proteins were up-regulated and 86 were down-regulated (Table 2). Most of the up-regulated proteins belonged to Metabolism, Processing, Oxidative processes, Trafficking, Transcription and Transport.

\section{Changes in protein associated with vesicular trafficking during fruit development}

In order to illustrate similarities and disparities between $\mathrm{dMS}$ and SC for the quantitation of protein changes during fruit development, we analyzed changes in proteins associated with vesicular trafficking and protein movements. The global changes in protein profiles and the metabolic processes associated with the quantitative protein changes during fruit development will be presented and discussed elsewhere (Katz et al., in preparation).

In this study, many small G-proteins and other proteins associated with a large number of cellular processes such as vesicle formation; vesicular traffic and docking, etc. [45-47] were found to be differentially expressed during fruit development (Tables 2, 3).

Table 2 Functional classification of proteins identified by dMS and SC workflows (see Experimental Procedures) after search of the iCitrus database.

\begin{tabular}{|c|c|c|c|c|c|c|c|c|c|c|c|c|c|c|c|c|}
\hline \multirow[b]{3}{*}{ Functional category } & \multicolumn{8}{|c|}{ Stage II vs. early Stage II } & \multicolumn{8}{|c|}{ Stage III vs. Stage II } \\
\hline & \multicolumn{2}{|l|}{ Up } & \multicolumn{2}{|c|}{ No Change } & \multicolumn{2}{|l|}{ Down } & \multicolumn{2}{|l|}{ Total } & \multicolumn{2}{|l|}{ Up } & \multicolumn{2}{|c|}{ No Change } & \multicolumn{2}{|l|}{ Down } & \multicolumn{2}{|l|}{ Total } \\
\hline & $\mathrm{dMS}$ & $\mathrm{SC}$ & dMS & $\mathrm{SC}$ & dMS & $\mathrm{SC}$ & dMS & $\mathrm{SC}$ & dMS & SC & dMS & $\mathrm{SC}$ & dMS & $\mathrm{SC}$ & $\mathrm{dMS}$ & $\mathrm{SC}$ \\
\hline Cell Cycle & 0 & 0 & 1 & 1 & 3 & 1 & 4 & 2 & 0 & 0 & 0 & 2 & 0 & 0 & 0 & 2 \\
\hline Cell Wall & 18 & 2 & 8 & 3 & 8 & 4 & 34 & 9 & 37 & 4 & 3 & 3 & 3 & 10 & 43 & 17 \\
\hline Energy & 26 & 4 & 23 & 11 & 35 & 24 & 84 & 39 & 24 & 10 & 12 & 20 & 4 & 2 & 40 & 32 \\
\hline Heat Shock/Chaperone & 66 & 25 & 40 & 15 & 29 & 8 & 135 & 48 & 80 & 21 & 55 & 24 & 0 & 10 & 135 & 55 \\
\hline Metabolism & 86 & 34 & 87 & 44 & 115 & 38 & 288 & 116 & 238 & 53 & 91 & 111 & 5 & 27 & 334 & 191 \\
\hline Oxidative processes & 32 & 11 & 39 & 11 & 34 & 11 & 15 & 33 & 90 & 20 & 18 & 24 & 6 & 5 & 114 & 49 \\
\hline Processing & 9 & 15 & 34 & 16 & 63 & 14 & 106 & 45 & 62 & 26 & 40 & 35 & 7 & 16 & 109 & 77 \\
\hline Signaling & 30 & 16 & 23 & 16 & 36 & 16 & 89 & 48 & 39 & 7 & 14 & 22 & 11 & 11 & 64 & 40 \\
\hline Structure & 48 & 2 & 13 & 5 & 20 & 10 & 81 & 17 & 25 & 1 & 10 & 2 & 30 & 8 & 65 & 11 \\
\hline Trafficking & 14 & 6 & 32 & 16 & 41 & 14 & 87 & 36 & 40 & 11 & 39 & 24 & 0 & 1 & 79 & 36 \\
\hline Transcription & 4 & 2 & 26 & 12 & 24 & 12 & 54 & 26 & 33 & 4 & 2 & 13 & 3 & 6 & 38 & 23 \\
\hline Translation & 65 & 10 & 35 & 28 & 113 & 32 & 213 & 70 & 43 & 5 & 87 & 39 & 10 & 28 & 140 & 72 \\
\hline Transport & 29 & 6 & 15 & 16 & 43 & 24 & 87 & 46 & 70 & 12 & 29 & 24 & 0 & 1 & 99 & 37 \\
\hline Unknown & 24 & 23 & 50 & 28 & 53 & 30 & 127 & 81 & 69 & 28 & 28 & 49 & 7 & 24 & 104 & 101 \\
\hline Sum. & 451 & 156 & 426 & 222 & 617 & 238 & 1494 & 616 & 850 & 202 & 428 & 392 & 86 & 149 & 1364 & 743 \\
\hline
\end{tabular}

Proteins were classified into 14 major groups and are represented according to fruit development stages comparisons according to the method used (dMS and $\mathrm{SC}$. 
Table 3 Vesicular trafficking-related proteins identified by dMS and SC.

\begin{tabular}{|c|c|c|c|c|c|c|c|c|c|c|c|c|c|}
\hline \multirow[b]{3}{*}{$\begin{array}{l}\text { Gene } \\
\text { Family }\end{array}$} & \multirow[b]{3}{*}{ Annotation } & \multirow[b]{3}{*}{$\begin{array}{l}\text { iCitrus } \\
\text { ID }\end{array}$} & \multirow[b]{3}{*}{$\begin{array}{l}\text { Blast Hit } \\
\text { TAIR ID }\end{array}$} & \multicolumn{5}{|c|}{ Stage II $(55 \mathrm{~mm})$ vs. early stage II $(35 \mathrm{~mm})$} & \multicolumn{5}{|c|}{ Stage III $(80 \mathrm{~mm})$ vs. Stage II $(55 \mathrm{~mm})$} \\
\hline & & & & \multicolumn{2}{|c|}{ dMS } & \multicolumn{3}{|c|}{ SC } & \multicolumn{2}{|c|}{ dMS } & \multicolumn{3}{|c|}{ SC } \\
\hline & & & & Peptides & Ratio & $\begin{array}{l}\text { Bayes } \\
\text { Factor }\end{array}$ & $\begin{array}{l}\text { Fold } \\
\text { Change }\end{array}$ & Direction* & Peptides & Ratio & $\begin{array}{l}\text { Bayes } \\
\text { Factor }\end{array}$ & $\begin{array}{c}\text { Fold } \\
\text { Change }\end{array}$ & Direction* \\
\hline \multirow[t]{17}{*}{ Rab } & RABA1a/ARA2 & 5282 & AT1G06400 & 3 & 0.03 & - & - & - & 2 & 2.85 & - & - & - \\
\hline & $\begin{array}{l}\text { RABA1d/ } \\
\text { Rab11B }\end{array}$ & 50939 & AT4G18800 & 7 & 0.025 & 1.34 & 1.52 & 0 & - & - & 0.95 & 1.53 & 0 \\
\hline & RABA1f & 23943 & AT5G60860 & 5 & 0.11 & 465 & 31.9 & -1 & - & - & 0.8 & 1.2 & 0 \\
\hline & $\begin{array}{l}\text { RABA2a/ } \\
\text { Rab11C }\end{array}$ & 33548 & AT1G09630 & 6 & 0.72 & 63362 & 23 & -1 & 2 & 7.43 & 31.8 & 4.5 & 1 \\
\hline & RABA2b & 27900 & AT1G07410 & 3 & 0.026 & 3302 & 28 & -1 & - & - & - & - & - \\
\hline & $\begin{array}{l}\text { RABB1b/ } \\
\text { Rab2C }\end{array}$ & 28361 & AT4G35860 & - & - & - & - & - & 3 & 33.41 & - & - & - \\
\hline & RABB1C & 57271 & AT4G17170 & 5 & 0.11 & 72 & 3.2 & -1 & 4 & 28.6 & 1555 & 5.02 & 1 \\
\hline & RABD1/FP8 & 44137 & AT3G11730 & 3 & 0.33 & 395 & 17.8 & -1 & - & & 0.9 & 1.45 & 0 \\
\hline & $\begin{array}{l}\text { RABD2a/ } \\
\text { Rab1b }\end{array}$ & 22194 & AT1G02130 & 3 & 0.07 & 1472 & 24 & -1 & 2 & 31.24 & 62.5 & 5.00 & 1 \\
\hline & $\begin{array}{l}\text { RABD2b/ } \\
\text { Rab1A }\end{array}$ & 21238 & AT5G47200 & 2 & 0.04 & - & - & - & - & - & - & - & - \\
\hline & RABE1a/Rab8 & 55887 & AT3G53610 & 3 & 0.03 & 54.9 & 3.6 & -1 & - & - & 1.04 & 1.5 & 0 \\
\hline & RABE1e/Rab8E & 58806 & AT3G09900 & 2 & 0.04 & - & - & - & - & - & - & - & - \\
\hline & $\begin{array}{l}\text { RABE1c/Rab8/ } \\
\text { ARA-3 }\end{array}$ & 21701 & AT3G46060 & 4 & 1.06 & 8.8 & 1.8 & 0 & 2 & 3.48 & 0.82 & 1.2 & 0 \\
\hline & RABG3d & 44916 & AT1G52280 & 2 & 0.01 & - & - & - & - & - & - & - & - \\
\hline & RABG3f/Rab7B & 30351 & AT3G18820 & 3 & 0.006 & 0.8 & 1.3 & 0 & 2 & 6.94 & 2.16 & 1.79 & 0 \\
\hline & $\begin{array}{l}\text { RABH1b/ } \\
\text { Rab6A }\end{array}$ & 53105 & AT2G44610 & 5 & 0.07 & 478 & 18.3 & -1 & - & - & 0.75 & 1.2 & 0 \\
\hline & RABH1e & 30604 & AT5G10260 & 2 & 0.05 & - & - & - & - & - & - & - & - \\
\hline \multirow[t]{4}{*}{ Arf } & ARLA1C & 26509 & AT3G49870 & 3 & 0.79 & 0.58 & 1.13 & 0 & 2 & 4.49 & 1.07 & 1.67 & 0 \\
\hline & ARFA1e & 422 & AT3G62290 & 3 & 0.13 & - & - & - & 3 & 26.62 & - & - & - \\
\hline & ARFA1f & 22081 & AT1G10630 & 5 & 0.15 & - & - & - & 6 & 19.71 & - & - & - \\
\hline & SAR1C & 34375 & AT4G02080 & - & - & - & - & - & 3 & 4.91 & - & - & - \\
\hline \multirow[t]{4}{*}{ Ran } & $\begin{array}{l}\text { STL2P/SEC12P- } \\
\text { Like }\end{array}$ & 54385 & AT2G01470 & - & - & 2319 & 5.37 & 1 & - & - & 0.67 & 1.04 & 0 \\
\hline & RANBP1 & 42600 & AT5G58590 & 5 & 0.5 & 3.4 & 2.8 & 0 & 7 & 129.80 & 0.6 & 1.98 & 0 \\
\hline & RANBP1b & 2905 & AT2G30060 & - & - & 1.3 & 4.2 & 0 & 5 & 130.08 & 280 & 22.3 & 1 \\
\hline & RAN3 & 57970 & AT5G55190 & 2 & 0.87 & 0.64 & 1.82 & 0 & 7 & 20.25 & 3.7 & 1.67 & 0 \\
\hline Rho & GP3/ROP4 & 29311 & AT1G75840 & 2 & 0.28 & - & - & 0 & - & - & - & - & - \\
\hline \multirow[t]{2}{*}{ GDI } & GDI1 & 34016 & AT2G44100 & - & - & 1.58 & 2.18 & 0 & 3 & 5.00 & 0.73 & 1.13 & 0 \\
\hline & GDI2-like & 876 & AT5G09550 & - & - & - & - & - & 2 & 3.11 & - & - & - \\
\hline \multirow{3}{*}{$\begin{array}{l}\text { VAMP/R- } \\
\text { SNARES }\end{array}$} & SEC22 & 58654 & AT1G11890 & 2 & 0.20 & 26.9 & 13.6 & -1 & - & - & 1.06 & 1.46 & 0 \\
\hline & VAP27-1 & 54676 & AT3G60600 & 2 & 0.77 & - & - & - & - & - & - & - & - \\
\hline & VAMP713 & 23669 & AT5G11150 & 2 & 1.41 & - & - & - & - & - & - & - & - \\
\hline \multirow[t]{2}{*}{$\begin{array}{l}\text { Qa- } \\
\text { SNARES }\end{array}$} & $\begin{array}{l}\text { SYP132 } \\
\text { (syntaxin 132) }\end{array}$ & 12539 & AT5G08080 & - & - & 3 & 6.2 & 0 & 2 & 3.21 & 1.25 & 1.65 & 0 \\
\hline & $\begin{array}{l}\text { VAM3 } \\
\text { (syntaxin 22) }\end{array}$ & 37248 & AT5G46860 & - & - & 1.35 & 1.86 & 0 & - & - & 4.5 & 2.3 & 0 \\
\hline $\begin{array}{l}\text { Qb- } \\
\text { SNARES }\end{array}$ & VTI11 & 24253 & AT5G39510 & 2 & 0.05 & 0.65 & 1.37 & 0 & - & - & 0.5 & 1.2 & 0 \\
\hline \multirow[t]{2}{*}{$\begin{array}{l}\text { QC- } \\
\text { SNARES }\end{array}$} & $\begin{array}{l}\text { SYP71 } \\
\text { (SYNTAXIN) }\end{array}$ & 27696 & AT3G09740 & - & - & 2.17 & 4.34 & 0 & - & - & - & - & - \\
\hline & ALPHA-SNAP2 & 2375 & AT3G56190 & - & - & 1.00 & 1.00 & 0 & - & - & 6.41 & 7.6 & 0 \\
\hline ESCRT III & SNF7.1 & 35782 & AT4G29160 & 4 & 1.31 & 4.88 & 2.99 & 0 & 7 & 597.36 & 106 & 5.5 & 1 \\
\hline
\end{tabular}


Table 3 Vesicular trafficking-related proteins identified by dMS and SC. (Continued)

\begin{tabular}{|c|c|c|c|c|c|c|c|c|c|c|c|c|c|}
\hline Dynamin & $\begin{array}{l}\text { ADL6 } \\
\text { (dynamin-like } \\
\text { protein 6) }\end{array}$ & 36589 & AT1G10290 & - & - & - & - & - & 2 & 6.63 & - & - & - \\
\hline \multirow[t]{16}{*}{ others } & SEC61 & 35474 & AT1G29310 & 3 & 0.10 & 171.70 & 17.65 & -1 & - & - & 1.00 & 1.4 & 0 \\
\hline & SEC14 & 30056 & AT1G72160 & 5 & 3.42 & 37.17 & 13.65 & 1 & 16 & 12.92 & 4.8 & 1.5 & 0 \\
\hline & PATL2 & 35474 & AT1G22530 & 3 & 0.104 & 170.5 & 17.65 & -1 & 3 & 6.83 & 1.04 & 1.43 & 0 \\
\hline & SCAMP & 34675 & AT1G32050 & 3 & 1.70 & 1.50 & 1.55 & 0 & 2 & 4.11 & 0.74 & 1.18 & 0 \\
\hline & $\begin{array}{l}\text { SC3 (secretory } \\
\text { carrier 3) }\end{array}$ & 30772 & AT1G61250 & 2 & 0.98 & 2.9 & 6.12 & 0 & - & - & 1.00 & 1.02 & 0 \\
\hline & SYT1 & 45523 & AT2G20990 & 4 & 8.7 & 0.3 & 1.5 & 0 & 4 & 2.64 & 1.2 & 1.6 & 0 \\
\hline & $\begin{array}{l}\text { COP-I } \\
\text { coatomer, B- } \\
\text { cOP } \alpha\end{array}$ & 29871 & AT2G21390 & 2 & 0.4 & 0.6 & 1.22 & 0 & 3 & 11.47 & 1.31 & 1.73 & 0 \\
\hline & $\begin{array}{l}\text { RTNLB3 } \\
\text { reticulon }\end{array}$ & 42672 & AT1G64090 & 2 & 0.53 & 2.1 & 3.7 & 0 & 2 & 2.31 & 0.72 & 1.48 & 0 \\
\hline & $\begin{array}{l}\text { RTNLB5 } \\
\text { reticulon }\end{array}$ & 13580 & AT2G46170 & - & - & 0.97 & 1.02 & 0 & - & - & 4.35 & 2.97 & 0 \\
\hline & $\begin{array}{l}\text { RTNLB6 } \\
\text { reticulon }\end{array}$ & 22293 & AT3G10260 & - & - & 1.24 & 1.4 & 0 & 2 & 36.56 & 187.81 & 5.76 & 1 \\
\hline & $\begin{array}{l}\text { clathrin heavy } \\
\text { chain }\end{array}$ & 57153 & AT3G08530 & - & - & 83.92 & 13.36 & -1 & - & - & 0.76 & 1.17 & 0 \\
\hline & $\begin{array}{l}\text { clathrin heavy } \\
\text { chain }\end{array}$ & 60690 & AT3G08530 & 2 & 0.05 & 63.7 & 13.65 & -1 & - & - & 46.45 & 10.98 & -1 \\
\hline & $\begin{array}{l}\text { Clathrin light } \\
\text { chain }\end{array}$ & 51128 & AT2G20760 & 2 & 119 & 2300591 & 11.55 & 1 & 2 & 1.8 & 0.8 & 1.2 & 0 \\
\hline & $\begin{array}{l}\text { Clathrin light } \\
\text { chain }\end{array}$ & 21278 & AT3G51890 & 2 & 118 & 1511 & 6.2 & 1 & - & - & 1.63 & 1.57 & 0 \\
\hline & $\begin{array}{l}\text { myosin heavy } \\
\text { chain }\end{array}$ & 38388 & AT4G31340 & - & - & 0.6 & 1.00 & 0 & - & - & 0.75 & 1.3 & 0 \\
\hline & $\begin{array}{l}\text { myosin heavy } \\
\text { chain }\end{array}$ & 37311 & AT1G06530 & 3 & 0.02 & 156 & 16 & -1 & - & - & 1.1 & 1.4 & 0 \\
\hline
\end{tabular}

* The column "direction" under spectral counting measurement represent expression direction, $1=$ up-regulated, $0=$ no change, $-1=$ down-regulated. Proteins identified by dMS were considered to be upregulated when expression fold $>2$, not changed when $0.5<$ fold $<2$ and down-regulated when fold change was $<2$. For SC Bayes factor of $>10$ was used for significance difference.

Several small G-proteins belonging to the sub-families RAB, ARF, RHO and RAN were differentially expressed during fruit development. For example, proteins belonging to the RAB-like sub-family (nomenclature according to Vernoud et al., [48]); RABA1a, RABA1 d, RABA1f, RABA2a, RABA2b, RABB1b, RABB1c, RABD1, RABD2a, RABD2b, RABE1a, RABE1c, RABE1e, RABG3 d, RABG3f, RABH1b and RABH1e were found to be differentially expressed (Table 3). During the transition between early Stage II to Stage II most of this group of proteins was down-regulated according to dMS, except for RABA2a and RABE1c. Similarly to dMS, SC showed that RABA1f, RABA2a, RABA2b, RABB1c, RABD1, RABD2a, RABE1a and RABH1b, were down-regulated while no changes were detected in RABA1 d, RABE1c and RABG3f. During the transition from Stage II to Stage III, RABA1a, RABA2a, RABB1b, RABB1c, RABD2a, RABE1c and RABG3f were shown to be up-regulated by dMS (Table 3). SC detected up-regulation only for RABA2a, RABB1c and RABD2a at these stages. Few members of the ADP-ribosylation factor (ARF) were also found to be differentially expressed during fruit development. ARFA1e and ARFA1f were down-regulated during the transition from early Stage II to Stage II. On the other hand, ARLA1c remained unchanged (Table 3). ARFA1e, ARFA1f, ARLA1c and SAR1 provide another example of the difference in accuracy between $\mathrm{dMS}$ and SC. While dMS indicated that these four proteins were up-regulated during the later stages of fruit development (Table 3), SC indicated no change. Four members of the RAN family, SEC12p, RANBP1, RANBP1b and RAN3 were identified in this study. The expression of RAN3 remained unchanged during the early stages of fruit development (as shown by both dMS and SC) but was up-regulated during the later stages. Both $\mathrm{dMS}$ and SC indicated that the expression of RANBP1b was up-regulated during the later stages of fruit development while only dMS showed up-regulation of RANBP1. SEC12p was up-regulated during the early stages and remained unchanged during the later stages of fruit development.

Among the members of the RHO family, ROP4 was down-regulated at earlier stages of development (Table 4). 
Interestingly, dMS showed that two RAB GDI (GDP-RAB dissociation inhibitors), GDI1 and GDI2-like were upregulated during the later stages of fruit development while only GDI1was identified by SC. Three R-SNAREs were identified; SEC22 that was down-regulated during the transition from early Stage II to Stage II, VAMP27-1 and VAMP713 were identified but were not found to be differentially expressed. Five Q-SNAREs were identified but only VTI11 (Qb-SNARE) was found to be down-regulated during early stages of development while SYP132 (Qa-SNARE, syntaxin) was found to be up-regulated during late stages of development. SNF7, a component of the endosomal ESCRT III complex that functions in cargo recognition and sorting [49], was up-regulated during the late stages of development. Additional proteins related to vesicular trafficking such as dynamin, COP-I coatomer, reticulon 3 and 6 , and proteins related to secretory membrane carriers such as SEC14, PATL2 and SYT1 were upregulated during the late stages of fruit development, while SEC 14, SYT1, and light chain of clathrin were upregulated during the transition from early Stage II to Stage II. Heavy chain of clathrin was down-regulated throughout development (Table 3).

Differential protein expression was also found in other important groups of proteins, actins and tubulins, key factors in trafficking, cell division and enlargement [50]. TUB1, TUA3, TUA4, TUB5, TUA6, TUB6 and TUB8 were down-regulated in the transition from early Stage II to Stage II (Table 4). TUB1, TUA4, TUB5, TUA6 and TUB6 were down-regulated further during the transition from Stage II to Stage III while TUB7 and TUB8 were up-regulated during this transition. Actins, driving vesicular movement towards their destination, showed significant changes during fruit development (Table 4). ACT1, ACT7, ACT8 and ACT11 were down-regulated during the transition from early stage II to stage II and were up regulated during the transition from stage II to stage III (Table 4).

Down-regulation of other proteins related to the vesicle movements such as CaM5 (which binds to the motor protein kinesin $[51,52]$ and myosin were detected (Table 4). Profilins, PFN1, PFN3 and PFN5, involved in actin polymerization and cytoskeleton organization did not change during the transition from early Stage II to Stage II, but PFN1 and PFN3 were up-regulated during the transition from Stage II to Stage III. Another protein, ADF4, involved in actin de-polymerization was down regulated during the transition to Stage III. Microtubule Associated Protein 65 (MAP65) and KIS (Tubulin cofactor A) involved in tubulin complex assembly and cell division [53,54], were down-regulated throughout fruit development (Table 4).

Transporters play a crucial role in cell growth and homeostasis, especially in specialized solute accumulating cells such as citrus juice cells. As expected, many changes in transporters protein expression were noted during fruit development (Table 5). During the transition from early Stage II to Stage III, there was a significant downregulation of subunits of lysosomal ATPases and cation transporters associated with $\mathrm{K}^{+}$- and $\mathrm{Na}^{+}$-coupled transport. On the other hand, only one plasma membranebound ATPase displayed down-regulation (similar to AHA8), while those similar to AHA2, AHA4 and AHA10 were not significantly changed. In general, these changes were noted using both dMS and SC. Most of the proteins that were down-regulated during the transition from early to Stage II, were up-regulated during the transition from Stage II to Stage III (Table 5), suggesting their role during fruit expansion. Similar results were seen with mitochondrial-bound proteins such as ACP4, ADP/ATP carriers and others. Two tonoplast monosaccharide transporters, TMT1 and TMT2 were up-regulated during the transition from early to stage II and TMT2 was further up-regulated during the later stages of fruit development. A dicarboxylate/tricarboxylate carrier was upregulated throughout development. Plasma membrane water channels PIP1B/PIP1;2, TMP-C/PIP1;4, PIP2;8/ PIP3B and PIP2;5/PIP2 D were down-regulated during the transition from early to Stage II according to SC (Table 5).

\section{Discussion}

In this study we describe a label-free shotgun approach to establish a proteomics workflow for the identification of the protein changes occurring during citrus fruit development. We analyzed and compared juice sac cells extracted from fruits at three stages of development. The end of Stage I (early Stage II), characterized by extensive cell division; Stage II, where cell division ceases and the juice cell sacs expand with the accumulation of large amounts of solutes and water; and Stage III, where the fruit matures and ripens [55,56]. It should be noted that it was practically impossible to extract juice sac cell proteins at Stage I (fruit diameter $\approx 10-15$ $\mathrm{mm}$ ) because at this stage the juice sac cells are not well developed.

Comparative proteomics studies in plants are still lagging behind studies done in mammalian cells and are predominantly performed by employing 2DE-gels [57]. Although differential proteomics studies employing label-free quantification have been published during the last few years $[9,10,24]$, in plants these studies are scarce $[26,43]$.

In order to employ an efficient proteomics study in citrus, a plant species lacking a full sequenced genome, we established a workflow that dealt with few of the problems arising from using a ESTs database. We created iCitrus, a database and interface that collected 
Table 4 Structure-related proteins identified by dMS and SC.

\begin{tabular}{|c|c|c|c|c|c|c|c|c|c|c|c|c|}
\hline \multirow[b]{3}{*}{ Annotation } & \multirow[b]{3}{*}{$\begin{array}{l}\text { iCitrus } \\
\text { ID }\end{array}$} & \multirow[b]{3}{*}{$\begin{array}{l}\text { Blast Hit } \\
\text { TAIR ID }\end{array}$} & \multicolumn{5}{|c|}{ Stage II $(55 \mathrm{~mm})$ vs. early stage II $(35 \mathrm{~mm})$} & \multicolumn{5}{|c|}{ Stage III $(80 \mathrm{~mm})$ vs. Stage II $(55 \mathrm{~mm})$} \\
\hline & & & \multicolumn{2}{|c|}{ dMS } & \multicolumn{3}{|c|}{$\mathrm{sC}$} & \multicolumn{2}{|c|}{ dMS } & \multicolumn{3}{|c|}{ sC } \\
\hline & & & Peptides & Ratio & $\begin{array}{l}\text { Bayes } \\
\text { Factor }\end{array}$ & $\begin{array}{l}\text { Fold } \\
\text { Change }\end{array}$ & Direction* & Peptides & Ratio & $\begin{array}{l}\text { Bayes } \\
\text { Factor }\end{array}$ & $\begin{array}{l}\text { Fold } \\
\text { Change }\end{array}$ & Direction* \\
\hline TUB1 (tubulin beta-1) & 33157 & AT1G75780 & 4 & 0.024 & - & - & - & 2 & 0.06 & - & - & - \\
\hline TUA3 (tubulin alpha-3) & 46363 & AT5G19770 & 4 & 0.07 & - & - & - & - & - & - & - & - \\
\hline TUA4 (tubulin alpha-4) & 22742 & AT1G04820 & 10 & 0.025 & 24.68 & 2.83 & -1 & & & 1473619 & 13.49 & -1 \\
\hline TUA4 (tubulin alpha-4) & 28975 & AT1G04820 & 10 & 0.025 & - & - & - & 4 & 0.16 & - & - & - \\
\hline TUA4 (tubulin alpha-4) & 37760 & AT1G04820 & 8 & 0.026 & 884.12 & 10.19 & -1 & 3 & 0.7 & 0.6 & 1.4 & 0 \\
\hline TUB5 (tubulin beta-5) & 30386 & AT1G20010 & 9 & 0.02 & 17.65 & 4.6 & -1 & 4 & 0.41 & 527 & 9.15 & -1 \\
\hline TUB5 (tubulin beta-5) & 32879 & AT1G20010 & 9 & 0.04 & 3125 & 46.15 & -1 & - & - & - & - & - \\
\hline TUB5 (tubulin beta-5) & 50323 & AT1G20010 & 10 & 0.02 & 27.89 & 14.3 & -1 & 3 & 0.4 & 16293 & 33.34 & -1 \\
\hline TUB5 (tubulin beta-5) & 51971 & AT1G20010 & 10 & 0.025 & 537 & 26.95 & -1 & 4 & 0.39 & 12048 & 32.23 & -1 \\
\hline TUB5 (tubulin beta-5) & 53023 & AT1G20010 & 9 & 0.033 & 3784 & 49.2 & -1 & - & - & - & - & - \\
\hline TUA6 (tubulin alpha-6) & 2232 & AT4G14960 & 7 & 0.044 & - & - & - & - & - & - & - & - \\
\hline TUA6 (tubulin alpha-6) & 48045 & AT4G14960 & 4 & 0.025 & - & - & - & 2 & 21.7 & - & - & - \\
\hline TUB6 (tubulin beta-6) & 54455 & AT5G12250 & 6 & 0.027 & - & - & - & & 2.18 & - & - & - \\
\hline TUB7 (tubulin beta-7) & 54189 & AT2G29550 & 2 & 0.6 & - & - & - & 2 & 2.19 & - & - & - \\
\hline TUB8 (tubulin beta-8) & 55174 & AT5G23860 & 5 & 0.022 & - & - & - & 3 & 45.85 & - & - & - \\
\hline $\mathrm{ACT} 1$ (actin 1) & 45172 & AT2G37620 & 3 & 0.3 & - & - & - & 3 & 22.49 & - & - & - \\
\hline ACT7 (actin 7) & 3401 & AT5G09810 & 6 & 0.025 & 42.61 & 2.24 & -1 & - & - & - & - & - \\
\hline ACT7 (actin 7) & 31765 & AT5G09810 & 6 & 0.22 & - & - & - & 5 & 17.50 & - & - & - \\
\hline ACT8 (actin 8) & 57479 & AT1G49240 & 13 & 0.04 & 20.5 & 2.12 & -1 & 8 & 21.93 & 20.36 & 2.12 & 1 \\
\hline ACT11 (actin 11) & 51444 & AT3G12110 & 4 & 0.26 & - & - & - & 3 & 27.16 & - & - & - \\
\hline CAM5 (Calmodulin 5) & 18478 & AT2G27030 & - & - & 7135 & 1.85 & -1 & - & - & 32767 & 2.69 & -1 \\
\hline CAM5 (Calmodulin 5) & 51416 & AT2G27030 & 7 & 0.15 & - & - & - & - & - & - & - & - \\
\hline KIS (KIESEL) & 26013 & AT2G30410 & - & - & 51.78 & 4.89 & -1 & - & - & 48.8 & 8.36 & -1 \\
\hline VLN3 (VILLIN 3) & 11096 & AT3G57410 & - & - & 1.19 & 3.00 & 0 & - & - & 1.55 & 1.74 & 0 \\
\hline $\begin{array}{l}\text { microtubule associated } \\
\text { protein (MAP65/ASE1) }\end{array}$ & 38803 & AT4G26760 & 4 & 0.03 & 95.54 & 28.3 & -1 & - & - & 135.6 & 13.6 & -1 \\
\hline PFN1/PRF1 (PROFILIN 1) & 4145 & AT2G19760 & 2 & 1.36 & - & - & - & 2 & 15.81 & 0.80 & 1.14 & 0 \\
\hline PFN3/PRF3 (PROFILIN 3) & 23065 & AT5G56600 & 3 & 1.47 & 0.85 & 1.4 & 0 & 2 & 15.81 & 1.4 & 3.8 & 0 \\
\hline PRF5 (PROFILIN5) & 5851 & AT2G19770 & - & - & 0.9 & 1.34 & 0 & - & - & 0.6 & 1.03 & 0 \\
\hline $\begin{array}{l}\text { ADF4 actin } \\
\text { depolymerizing }\end{array}$ & 7407 & AT5G59890 & - & - & 6.8 & 5.2 & 0 & - & - & 28.89 & 10.4 & -1 \\
\hline
\end{tabular}

* The column "direction" under spectral counting measurement represent expression direction, $1=$ up-regulated, $0=$ no change, $-1=$ down-regulated. Proteins identified by dMS were considered to be up-regulated when expression fold $>2$, not changed when $0.5<$ fold $<2$ and down-regulated when fold change was $<2$. For spectral counting Bayes factor of $>10$ was used for significance difference.

sequences from three different sources, HarvEST:Citrus http://harvest.ucr.edu/, NCBI's Citrus unigenes and NCBI's Citrus proteins http://www.ncbi.nlm.nih.gov/ Taxonomy/Browser/wwwtax.cgi? $\operatorname{mode}=$ Info\&id $=2711 \& \mathrm{lvl}=3 \&$ lin $=\mathrm{f} \& \mathrm{keep}=1 \& \mathrm{srch}$ mode $=1 \&$ un lock to create one unified database with reduced redundancy for mass spectra search. iCitrus was created to provide a compact database for the identification of citrus proteins and a more accurate quantitative expression measurements. The iCitrus interface enabled a fast identification of lists of accessions including Arabidopsis homologs, and the use of bioinformatics tools such as MapMan, AraCyc and Cytoscape (Katz et al. in preparation).
The iCitrus resource is essentially an interface that can be used to access pre-calculated Blast results. iCitrus itself does not make or summarize GO assignments based on rules that weight GO terms from various hits; this is the (perfectly reasonable) philosophy behind Blast2GO and related tools. We chose to allow users, instead of iCitrus, to determine if they trust and adopt particular annotations or not. We took this approach to allow individual users to use specific knowledge of protein families or taxonomical differences (i.e. Citrus versus Arabidopsis) to influence their interpretation of the BLAST results. In addition, there may be cases in which GO annotation is absent in the BLAST results against Arabidopsis or Viridiplantae, but a consensus could 
Table 5 Transport-related proteins identified by dMS and SC.

\begin{tabular}{|c|c|c|c|c|c|c|c|c|c|c|c|c|}
\hline \multirow[b]{3}{*}{ Annotation } & \multirow[b]{3}{*}{$\begin{array}{l}\text { iCitrus } \\
\text { ID }\end{array}$} & \multirow[b]{3}{*}{$\begin{array}{l}\text { Blast Hit } \\
\text { TAIR ID }\end{array}$} & \multicolumn{5}{|c|}{ Stage II $(55 \mathrm{~mm})$ vs. early stage II $(35 \mathrm{~mm})$} & \multicolumn{5}{|c|}{ Stage III $(80 \mathrm{~mm})$ vs. Stage II $(55 \mathrm{~mm})$} \\
\hline & & & \multicolumn{2}{|c|}{ dMS } & \multicolumn{3}{|c|}{ SC } & \multicolumn{2}{|c|}{$\mathrm{dMS}$} & \multicolumn{3}{|c|}{ SC } \\
\hline & & & Peptides & Ratio & $\begin{array}{l}\text { Bayes } \\
\text { Factor }\end{array}$ & $\begin{array}{l}\text { Fold } \\
\text { Change }\end{array}$ & Direction* & Peptides & Ratio & $\begin{array}{l}\text { Bayes } \\
\text { Factor }\end{array}$ & $\begin{array}{l}\text { Fold } \\
\text { Change }\end{array}$ & Direction* \\
\hline $\mathrm{Ca}^{2+}$-ATPase & 45644 & AT1G07670 & - & - & 1.2 & 2.9 & 0 & 2 & 20.88 & 27.99 & 4.99 & 1 \\
\hline $\mathrm{Ca}^{2+} / \mathrm{Na}^{+}$exchanger & 47787 & AT1G53210 & 2 & 0.27 & 14.27 & 3.00 & -1 & 2 & 9.04 & 0.71 & 1.15 & 0 \\
\hline $\mathrm{KEA} 2\left(\mathrm{~K}^{+} / \mathrm{H}^{+}\right.$antiporter $)$ & 36862 & AT4G00630 & 2 & 0.40 & 1.41 & 1.75 & 0 & - & - & 0.8 & 1.2 & 0 \\
\hline $\begin{array}{l}\text { porin, putative; voltage- } \\
\text { dependent anion } \\
\text { channel }\end{array}$ & 23759 & AT3G01280 & 2 & 0.19 & 13.9 & 6.34 & -1 & 2 & 6.09 & 15.91 & 4.81 & 1 \\
\hline $\begin{array}{l}\text { DET3 C subunit C (V- } \\
\text { type } \mathrm{H}^{+} \text {- ATPase) }\end{array}$ & 58235 & AT1G12840 & 3 & 0.27 & 45.53 & 3.26 & -1 & - & - & 1.2 & 1.48 & 0 \\
\hline $\begin{array}{l}\text { AVP1 (vacuolar H } \\
+ \text { +-PPiase) }\end{array}$ & 36100 & AT1G15690 & 4 & 2.31 & 1.1 & 1.2 & 0 & & & 2.76 & 1.63 & 0 \\
\hline VHA-A & 27256 & AT1G78900 & 13 & 0.04 & 1011648 & 3.99 & -1 & 12 & 9.94 & 38.82 & 2.2 & 1 \\
\hline VHA-A3 (V-ATPase) & 49974 & AT4G39080 & 4 & 0.44 & - & - & - & 3 & 4.01 & - & - & - \\
\hline $\begin{array}{l}\text { V-type ATPase subunit } \\
\text { B1 }\end{array}$ & 3683 & AT1G76030 & 8 & 0.05 & - & - & - & 5 & 13.78 & - & - & - \\
\hline $\begin{array}{l}\text { V-type ATPase subunit } \\
\text { B2 }\end{array}$ & 62399 & AT4G38510 & 11 & 0.06 & - & - & - & 9 & 11.25 & - & - & - \\
\hline $\begin{array}{l}\text { V-type ATPase subunit } \\
\text { B3 }\end{array}$ & 37671 & AT1G20260 & 11 & 0.06 & 140.60 & 2.13 & -1 & 9 & 11.25 & 1004 & 2.64 & 1 \\
\hline V-type ATPase subunit D & 23422 & AT3G58730 & - & - & 34.4 & 5.4 & -1 & - & - & 1.55 & 1.45 & 0 \\
\hline $\begin{array}{l}\text { V-type ATPase subunit } \\
\text { E1 }\end{array}$ & 52391 & AT4G11150 & - & - & 19.83 & 3.22 & -1 & 2 & 5.12 & 7.23 & 1.94 & 0 \\
\hline $\begin{array}{l}\text { VMA10 (V-type ATPase } \\
\text { 10); Subunit G }\end{array}$ & 28722 & AT3G01390 & 3 & 0.28 & 36.6 & 2.8 & -1 & - & - & 0.15 & 1.78 & 0 \\
\hline V-type ATPase subunit $\mathrm{H}$ & 38700 & AT3G42050 & 6 & 0.25 & 36.6 & 2.82 & -1 & 4 & 13.57 & 0.58 & 1.06 & 0 \\
\hline AHA2 $\left(\mathrm{H}^{+}\right.$-ATPase 2$)$ & 50370 & AT4G30190 & 3 & 0.53 & 0.98 & 1.23 & 0 & 4 & 11.79 & 1.75 & 1.49 & 0 \\
\hline AHA4 ( $\mathrm{H}^{+}$- ATPase 4) & 28397 & AT3G47950 & 3 & 1.14 & 11055 & 20.4 & -1 & 3 & 7.40 & 0.9 & 1.5 & 0 \\
\hline AHA8 (H+ $\mathrm{H}^{+}$ATPase 8) & 56228 & AT3G42640 & 2 & 0.35 & - & - & - & 2 & 13.60 & - & - & - \\
\hline $\begin{array}{l}\text { AHA10 (Autoinhibited } \mathrm{H} \\
{ }^{+}-\text {ATPase isoform 10) }\end{array}$ & 56764 & AT1G17260 & 4 & 1.13 & 5.8 & 1.55 & 0 & 4 & 41.48 & 1.36 & 1.19 & 0 \\
\hline $\mathrm{H}^{+}$- ATPase & 42025 & AT3G28710 & 2 & 0.11 & 335 & 18.72 & -1 & 2 & 17.27 & 22.04 & 4.37 & 1 \\
\hline $\begin{array}{l}\text { TMT1 (tonoplast } \\
\text { monosaccharide } \\
\text { transporter1) }\end{array}$ & 44853 & AT1G20840 & 3 & 24.79 & 3.0 & 1.1 & 0 & - & - & 382 & 5.1 & 1 \\
\hline $\begin{array}{l}\text { TMT2, (tonoplast } \\
\text { monosaccharide } \\
\text { transporter } 2\end{array}$ & 41259 & AT4G35300 & 8 & 32.69 & 16121 & 2.64 & 1 & 6 & 15.26 & 9.5 & 1.9 & 0 \\
\hline $\begin{array}{l}\text { GPT2 (glucose-6- } \\
\text { phosphate/phosphate } \\
\text { translocator 2) }\end{array}$ & 44184 & AT1G61800 & 2 & 0.10 & 28.2 & 12.3 & -1 & - & - & 0.8 & 1.2 & 0 \\
\hline mannitol transporter & 32978 & AT2G16130 & - & - & 439 & 18.8 & -1 & - & - & 5.8 & 3.2 & 0 \\
\hline LPT(lipid transfer protein) & 45077 & AT1G27950 & 2 & 0.01 & 5258.00 & 22.44 & -1 & - & - & - & - & - \\
\hline LTP3 & 58907 & AT5G59320 & - & - & 2.86 & 4 & 0 & - & - & 7447 & 21.8 & -1 \\
\hline $\begin{array}{l}\text { PDR6/PDR6 (pleiotropic } \\
\text { drug resistance 6); } \\
\text { ATPase }\end{array}$ & 26072 & AT2G36380 & - & - & 4.5 & 7.11 & 0 & - & - & 49.8 & 3.9 & 1 \\
\hline $\begin{array}{l}\text { PDR11/PDR11 } \\
\text { (pleiotropic drug } \\
\text { resistance 11); ATPase }\end{array}$ & 52044 & AT1G66950 & - & - & - & - & - & 2 & 11.74 & 1.18 & 1.56 & 0 \\
\hline $\begin{array}{l}\text { PDR12/(PLEIOTROPIC } \\
\text { DRUG 12); ATPase }\end{array}$ & 19314 & AT1G15520 & - & - & 0.98 & 1.03 & 0 & 2 & 14.97 & 5.44 & 3.46 & 0 \\
\hline $\begin{array}{l}\text { MAPR2 (membrane- } \\
\text { associated progesterone } \\
\text { binding protein 2) }\end{array}$ & 28962 & AT2G24940 & 3 & 1.62 & 1.57 & 1.65 & 0 & 3 & 45.68 & 1.38 & 1.69 & 0 \\
\hline
\end{tabular}


Table 5 Transport-related proteins identified by dMS and SC. (Continued)

\begin{tabular}{|c|c|c|c|c|c|c|c|c|c|c|c|c|}
\hline $\begin{array}{l}\text { MRP4 (multidrug } \\
\text { resistance-associated } \\
\text { protein 4) }\end{array}$ & 46730 & AT2G47800 & 2 & 1.36 & 2.62 & 2.64 & 0 & 5 & 58.12 & 19.3 & 2.6 & 1 \\
\hline $\begin{array}{l}\text { PGP7 (P-GLYCOPROTEIN } \\
\text { 7); ATPase }\end{array}$ & 10552 & AT5G46540 & - & - & 2.06 & 5.56 & 0 & - & - & 10.4 & 3.6 & 1 \\
\hline $\begin{array}{l}\text { PIP1B (plasma } \\
\text { membrane intrinsic } \\
\text { protein 1;2); water } \\
\text { transport }\end{array}$ & 18285 & AT2G45960 & - & - & 149.18 & 27.06 & -1 & - & - & - & - & - \\
\hline $\begin{array}{l}\text { PIP2;8/PIP3B (plasma } \\
\text { membrane intrinsic } \\
\text { protein 2;8); water } \\
\text { channel }\end{array}$ & 25444 & AT2G16850 & - & - & 462 & 23 & -1 & - & - & 0.9 & 1 & 0 \\
\hline $\begin{array}{l}\text { PIP2;5/PIP2 D (plasma } \\
\text { membrane intrinsic } \\
\text { protein 2;5); water } \\
\text { channel }\end{array}$ & 41682 & AT3G54820 & - & - & 635.26 & 39.02 & -1 & - & - & - & - & - \\
\hline $\begin{array}{l}\text { TMP-C (plasma } \\
\text { membrane intrinsic } \\
\text { protein 1;4); water } \\
\text { channel }\end{array}$ & 28678 & AT4G00430 & 3 & 0.11 & 35.06 & 10.97 & -1 & - & - & 2.76 & 2.70 & 0 \\
\hline protein transporter & 51128 & AT2G20760 & 3 & 30 & 0.2 & 1.6 & 0 & 2 & 1.80 & 0.84 & 1.22 & 0 \\
\hline protein transporter & 21278 & AT3G51890 & 2 & 118.94 & 1510 & 6.2 & 1 & - & - & 1.63 & 1.57 & 0 \\
\hline $\begin{array}{l}\text { TOM20-3 (translocase of } \\
\text { outer membrane) }\end{array}$ & 33905 & AT3G27080 & 4 & 0.45 & 0.6 & 1.16 & 0 & 3 & 4.75 & 18.02 & 2.97 & 1 \\
\hline ACP4 (acyl carrier 4) & 25090 & AT4G25050 & 3 & 0.34 & 3.1 & 2.27 & 0 & - & - & 13.4 & 7.8 & 1 \\
\hline AAC2 (ADP/ATP carrier) & 53189 & AT5G13490 & 8 & 0.27 & 16767 & 10.36 & -1 & 5 & 21.36 & 1.01 & 1.02 & 0 \\
\hline AAC3 (ADP/ATP carrier) & 26451 & AT4G28390 & 10 & 0.22 & 1040 & 3.48 & -1 & 6 & 76.16 & 32.95 & 2.75 & 1 \\
\hline $\begin{array}{l}\text { mitochondrial phosphate } \\
\text { transporter }\end{array}$ & 44051 & AT5G14040 & 4 & 0.10 & 10.8 & 3 & -1 & 2 & 4.29 & 0.79 & 1.2 & 0 \\
\hline $\begin{array}{l}\text { PDE120 protein import } \\
\text { (Tic40) }\end{array}$ & 57128 & AT5G16620 & 2 & 0.34 & - & - & - & - & - & - & - & - \\
\hline di/tricarboxylate carrier & 39221 & AT5G19760 & 5 & 56.47 & 0.52 & 1.49 & 0 & 2 & 25.92 & 0.69 & 1.13 & 0 \\
\hline $\begin{array}{l}\text { TOM22-V (translocase } \\
\text { outer mitochondrial } \\
\text { membrane) }\end{array}$ & 38717 & AT5G43970 & - & - & 160 & 17.8 & -1 & - & - & 2.98 & 2.65 & 0 \\
\hline Lipocalin & 23197 & AT5G58070 & 2 & 29.74 & 44.2 & 4.3 & 1 & 3 & 10.49 & 40.34 & 2.3 & 1 \\
\hline
\end{tabular}

* The column "direction" under spectral counting measurement represent expression direction, $1=$ up-regulated, $0=$ no change, $-1=$ down-regulated. Proteins identified by dMS were considered to be up-regulated when expression fold $>2$, not changed when $0.5<$ fold $<2$ and down-regulated when fold change was $<2$. For spectral counting Bayes factor of $>10$ was used for significance difference.

emerge from the descriptive text accompanying a hit. We think this combined approach of manual annotation with the assistance of pre-computed BLAST results is more effective when predicting functional information for a not well-annotated organism like Citrus.

Two widely used, but fundamentally different, labelfree methods for quantification were used in this study; peak integration (dMS) and spectral counting (SC). For dMS, we used a two-fold change as a threshold for differential expression of the identified proteins [25] and a Bayes factor of 10 for spectral counting [58]. Such a stringent threshold is needed because the protein ratios are calculated by averaging the intensity weight of peptide ratios, and because the number of peptides identifying each protein is highly variable. In most cases, both methods identified similar proteins with some discrepancies (Figure 4a). These discrepancies derived from the way SIEVE (for dMS) and Scaffold (for SC) handled the peptides information. Scaffold is able to identify peptides in similar proteins and group them together, thus identifying database redundancy, on the other hand, SIEVE does not group similar proteins. When we compare the number of identified proteins by the two methods using the corresponding Arabidopsis homologs of each iCitrus accession identified (Figure 4b) the differences decreased significantly, particularly for dMS (Figure 4). Yet, additional redundancy could arise from possible gene families in Citrus. The wide range of Citrus species used to create HarvEST:Citrus database including Citrus sinensis, Citrus paradise, Citrus unshiu, C. reticulata, C. jambhiri, C. aurantium, C. clementina, C. macrophylla and Poncirus trifoliate, 
consists of sequences that are similar but not identical therefore were not screened out from the iCitrus dataset. In addition, some of the sequences in the database that might originate from the same unigene did not overlap therefore could not be assembled, contributing to the difference in number of proteins identified (Table 1).

Currently, non-overlapping sequences cannot be assembled until more ESTs can be produced to cover the missing gaps or until the Citrus genome is fully sequenced [59]. A significant number of proteins (144 in dMS and 118 in SC in the Stage II vs. early Stage II comparison, and 119 in dMS and 255 proteins in SC, in the Stage III vs. Stage II comparison) were identified by only one of the methods due to the inherent differences of dMS and SC workflows. SEQUEST and SIEVE (dMS workflow) use protein probability cut-off based on false discovery rate (FDR) according to the Decoy method [60]. X!Tandem, Scaffold and Qspec (SC workflow) use peptide identification probability criteria as specified by the Peptide Prophet algorithm [61]. The different workflows affect some of the proteins identification. The performance of the SC method depends strongly on the depth of the MS/MS sampling because ratios by SC are most significant for proteins with large numbers of product ion spectra, while ratios by dMS are most significant for proteins with large numbers of overlapping peptide ions [25]. This also explains the higher percentage of proteins that were found to be significantly different by dMS and not significant by SC (Figures 3, 5a). Therefore, dMS provides more accurate measurements of compared samples while SC is faster and easier to use. Our data show that dMS is more accurate in measuring differences in protein expression [25]. dMS provide rich information of the LC-MS data but requires a massive computational effort to be spent on processing the data including background filtering, peak frame detection and alignment $[62,63]$. Spectral counting is conceptually simpler and can be as sensitive as dMS in terms of detection range while retaining linearity $[25,30,64]$. Nevertheless, SC is less accurate in detecting differences in protein expression, in particular for less abundant proteins. Our results clearly show that the integrated use of both methods for quantification increases the power for detecting changes in shotgun proteomics experiments, and that both methods should be use in combination to gain insight of the complex protein network and a complete identification of its components.

Changes in a large number of small GTPases were identified during citrus fruit development. The expression of a relatively large number of members of the RAB, ARF, RHO and RAN families of small GTPases changed during the different stages. Although we cannot assign specific roles to all of these proteins, they clearly indicate a different role(s) of these members during the stages of citrus juice sac cell development. Vesicular trafficking is essential for fruit development [65-67]. During the Stage I there is intensive cell division [56]. Cytoskeleton elements (actins, tubulins, etc.) together with small G-proteins and coatomer complexes are vital to cell division, cell plate formation, cell polarity, etc. [68]. The expression of many of these proteins decreased during the transition from early Stage II to Stage II. This correlated well with the attenuation of cell division in the growing fruit and the prevalence of cell expansion. This notion was reinforced by the notable increase in expression of other small GTPases, auxiliary proteins and cytoskeletal components. Similar to the small G-proteins, changes in the expression of proteins associated with vesicular movements, docking and fusion were seen. In addition to different SNAREs (Qa, $\mathrm{Qb}, \mathrm{Qc}$, syntaxins, etc.), there was changes in COPI coatomers, clathrin, dynamin, and others suggesting the occurrence of endocytosis, exocytosis and vesicular trafficking during fruit development. Notably, while the expression of plasma membrane-associated $\mathrm{H}^{+}$-ATPases did not change during the early stages of development, changes in endosomal-associated $\mathrm{H}^{+}$-ATPases (V-type) paralleled the changes seen in the secretory and vesicular trafficking machinery. V-type ATPases and organellar acidification is essential for vesicular trafficking along exocytotic and endocytotic pathways [69,70].

Although significant changes in sugar contents and sugar homeostasis are expected during fruit development $[71,72]$, changes in expression of only two putative vacuolar monosaccharide transporters (TMT1 and TMT2) were noted. A plausible explanation is that the expression of other sugar transporters did not change (although they could have been modified by post-translational mechanisms). In support of this notion, Etxeberria et al. $[73,74]$ demonstrated a mechanism of sugar transport into the juice sac cells and sucrose into the vacuoles that is mediated by endocytosis and intracellular vesicular trafficking. The protein inventory developed in this work, provides a preliminary glance at the function(s) of these proteins during the different stages of fruit development and in particular during cell division (Stage I, early Stage II) and cell expansion (Stage II) and assimilate mobilization, sugar accumulation and processes regulating fruit maturation and ripening.

In conclusion, we developed a workflow for the analysis and identification of proteins during fruit development in citrus, a non-model plant, using comparative label-free shotgun proteomics. We established iCitrus, a comprehensive sequence database by merging three major sources of sequences and improving the annotation of existing unigenes. iCitrus provided a useful 
bioinformatics tool for the high throughput identification of citrus proteins. Two methods for label-free based shotgun proteomics were used and compared; peak integration (or differential mass-spec) and spectral counting. We have identified approximately 1500 citrus protein accessions expressed in fruits and quantified their expression changes during fruit development. Our results showed that both methods can provide significant information on protein changes, with dMS providing higher accuracy. Our results clearly suggest that dMS and SC are matching, broadening the identification spectrum and providing complementary data on the change trends during the particular processes being compared.

\section{Methods}

\section{Plant material, protein extraction and precipitation}

Orange Navel fruits at three different developmental stages, early stage II ( $35 \mathrm{~mm}$ in fruit diameter), stage II (55 $\mathrm{mm})$ and stage III $(80 \mathrm{~mm})$ [55] were obtained from the Lindcove Research Center, University of California, Exeter, CA. Juice sacs were collected from at least 20 fruits and pooled at each stage. Two independent biological repetitions from two consecutive years were used and proteins were isolated as described before [18]. Soluble proteins were precipitated using a chloroform/methanol extraction method as described by Wessel and Flugge [75]. The samples were resuspended with $100 \mu \mathrm{l}$ of $1 \%$ Acetonitrile and sonicated for $10 \mathrm{~min}$ and centrifuged at $10,000 \mathrm{~g}$ for $3 \mathrm{~min}$. The supernatant was spin-dialyzed into $50 \mathrm{mM}$ ammonium-bicarbonate (AMBIC), then prepared for MS analysis using standard reduction, alkylation, and tryptic digest procedures [76]. Dichloromethane was added (50/50 v/v with aqueous digest) before vortexing for $1 \mathrm{~min}$. Samples were centrifuged for $5 \mathrm{~min}$ at 10,000 $\mathrm{g}$ in a microcentrifuge and the upper layer-containing peptides dried down and the peptides resolubilized in $2 \%$ acetonitrile/0.1\% trifluoroacetic acid for LC-MS/MS analysis.

Membrane-bound proteins were spin-dialyzed into $50 \mathrm{mM}$ AMBIC. An endo-polygalacturonanase (Megazyme) was employed to degrade pectins overnight at room temperature and the suspensions centrifuged and the pellets retained. Membranes were resolubilized in $50 \mathrm{mM}$ AMBIC and digested with trypsin. The suspension was centrifuged $10 \mathrm{~min}$ at $10,000 \mathrm{~g}$ and the supernatant containing tryptic peptides retained. Delipidation was performed with dichloromethane and the peptides resolubilized in $2 \%$ acetonitrile $/ 0.1 \%$ trifluoroacetic acid for LC-MS/MS analysis.

\section{Mass Spectrometry and Data Analysis}

Digested peptides were separated by reversed-phase chromatography using a Waters nanoACQUITY-UPLC system (Milford, MA), with a Waters BEH C $181.7 \mu \mathrm{m}$, $100 \mu \mathrm{m} \times 10 \mathrm{~cm}$ column. A binary solvent gradient was employed; buffer A was composed of $0.1 \%$ formic acid and buffer B composed of $100 \%$ acetonitrile (CAN). The 120 min gradient consisted of the steps $2-45 \%$ buffer B in $40 \mathrm{~min}, 45-80 \%$ buffer $\mathrm{B}$ in $65 \mathrm{~min}$, hold for $1 \mathrm{~min}$, $80-2 \%$ buffer B in $4 \mathrm{~min}$, then hold for $10 \mathrm{~min}$. Separated peptides were analyzed in a Thermo-Scientific LTQ-FT Ultram mass-spectrometer (San Jose, CA) with a Michrom captive spray nano-electrospray ionization source at a flow rate of $2 \mu \mathrm{l} / \mathrm{min}$. MS and MS/MS spectra were acquired using a top 4 method, where the 4 most abundant ions in the MS scan were selected for automated low energy Collision-induced Dissociation (CID) with a $30 \mathrm{~s}$ exclusion time and repeat count of 2 . The FTMS scan was obtained for the $\mathrm{m} / \mathrm{z}$ range 300 $1400 \mathrm{Da}$ at 50,000 resolution. An isolation width of $2.5 \mathrm{Da}$ was used for ITMS, and a normalized collision energy of $35 \%$ was used for the fragmentation. Five technical repeats of each pooled sample (older vs younger fruit) were each analyzed by SIEVE using blanks (washes) between each sample run.

\section{Protein Identification and Validation, dMS workflow}

Tandem mass spectra were extracted with Xcalibur version 2.0.7. All MS/MS samples were analyzed using SEQUEST (Protein Discoverer 1.1; Thermo-Scientific, San Jose, CA). SEQUEST was set up to search a FASTA file of the iCitrus Protein Database (see below), assuming the digestion enzyme trypsin. SEQUEST was searched with a peptide ion mass tolerance of $25 \mathrm{ppm}$ and a fragment ion mass tolerance of $1.0 \mathrm{Da}$. Oxidation of methionine and iodoacetamide derivative of cysteine was specified in SEQUEST as possible modifications. DTASelect software was used to filter out low score matching. The filtering criteria consisted of Crosscorrelation (xcorr) values larger than 1.5 for singlecharged ions, 2.2 for double-charged ions, and 3.3 for triple-charged ions, for both half or fully tryptic peptides. This resulted in a false discovery rate of less than $5 \%$ using a decoy search strategy.

Differential Expression mass spectrometry, dMS workflow Samples were analyzed using a Thermo Scientific LTQFT mass-spectrometer and a Michrom-Paradigm HPLC. Peptides were separated using a $200 \mu \mathrm{m} \times 15 \mathrm{~cm}$ Michrom Magic C18 reverse-phase column over $45 \mathrm{~min}$ using an acetonitrile gradient of $2 \%-60 \%$. The massspectrometer was set to acquire spectra in standard top 3 method where 1 high resolution scan (100 K resolution) was acquired every sec with subsequent MS/MS spectra acquired in the LTQ simultaneously.

Samples were analyzed using SIEVE (Thermo Scientific, San Jose Ca). SIEVE is a label-free-differential expression package that aligns the MS spectra over time from different experimental conditions and then determines features 
in the data $(\mathrm{m} / \mathrm{z}$ and retention time pairs) that differ across the different conditions. These differences were assigned using various statistics methods such as a P-Value and standard deviation and then sorted based on significance [10], based on the values obtained from the data of each biological replicate. Label free proteomic profiling was accomplished using SIEVE 1.3 (Thermo Scientific, San Jose, CA). The following parameters were set to align the retion time and generate the frames needed for abundance calculations. Alignment Parameters; Alignment Bypass $=$ False, Correlation Bin Width $=1$, RT Limits For Alignment $=$ True, Tile Increment $=150$, Tile Maximum $=300$, Tile Size $=300$, Time Threshold $=0.6$. Frame Parameters; AVGCharge Processor $=$ False, MS2 Corr Processor $=$ False, M/Z Min = $300, \mathrm{M} / \mathrm{Z} \operatorname{Max}=1,400$, Frame time Width $(\mathrm{min})=5.0 \mathrm{~min}-$ utes, Frame $M / Z$ width $=0.02$ da, Search Window $\%=50 \%$, Retention Time Start $=5.0 \mathrm{~min}$, Retention Time Stop $=110$ min, Peak Intensity threshold $=50,000$, Processor Modules = Isotagger V1.1, PCA V1.0. Significance was calculated within SIEVE using a standard T-test and results were filtered for a minimum of two peptides identified per protein (using the identification criteria stated in this method section) with frames having a $p$ value of less than 0.05 .

Tandem mass-spectra from peptide features that are considered differentially expressed across conditions are then searched using SEQUEST against iCitrus (see below). Search results were filtered for a False Discovery rate of $5 \%$ employing a decoy search strategy utilizing a reverse database [60].

\section{Protein Identification and Validation for Spectral counting} Tandem mass-spectra were extracted by Bioworks-3.3. Charge state de-convolution and de-isotoping were not performed. All MS/MS samples were analyzed using X! Tandem http://www.thegpm.org; version TORNADO (2008.02.01.2)). X! Tandem was set up to search the 62,415 entries of iCitrus (see below) assuming the digestion enzyme trypsin. X! Tandem was searched with a fragment ion mass tolerance of $0.40 \mathrm{Da}$ and a parent ion tolerance of $25 \mathrm{ppm}$. Iodoacetamide derivative of cysteine was specified in X! Tandem as a fixed modification. Deamidation of asparagine, oxidation of methionine, sulphone of methionine, tryptophan oxidation to formylkynurenin of tryptophan and acetylation of the $\mathrm{N}$-terminus were specified in $\mathrm{X}$ ! Tandem as variable modifications. Different tandem MS programs were used (SEQUEST for dMS and X!Tandem for Spectral Counting) because of licensing restriction and limited access to SEQUEST that would have generated significant time delays in the data analysis. Nonetheless, the use of SEQUEST or X!Tandem would have make little or no difference. In addition, in this report we aim at comparing overall methodology (i.e. dMS versus SC) and not their individual components.

\section{Criteria for protein identification for Spectral Counting} Scaffold 2.06.00 (Proteome Software Inc., Portland, OR) was used to validate MS/MS-based peptide and protein identifications. Peptide identifications were accepted if they could be established at greater than $80.0 \%$ probability as specified by the Peptide Prophet algorithm [61]. Protein identifications were accepted if they could be established at greater than $95.0 \%$ probability and contained at least 2 identified peptides. Protein probabilities were assigned by the Protein Prophet algorithm [77]. Proteins that contained similar peptides and could not be differentiated based on MS/MS analysis alone were grouped to satisfy the principles of parsimony.

\section{Statistical Analysis for Spectral Counting}

Unweighted Spectral counts for the identified proteins obtained from the samples corresponding to two consecutive growth seasons were exported from Scaffold and analyzed using QSpec [58] for significance analysis. Proteins were considered significantly different across sample conditions if QSpec reported a Bayes factor of $>10$. This corresponds to a false discovery rate (FDR) of approximately $5 \%$.

\section{Proteomics Data Set}

The data associated with this manuscript may be downloaded from ProteomeCommons.org Tranche using the following hash:

Cf3G8KatEeCbDv2kV1Gnw4njaSYARJgmtyzYl +5764Gsbb/M3LX+/oo1zcHnHK1Gs0ukuBM5Rk + Q1t5hpia109pVPXkAAAAAAAAoLg==The hash may be used to prove exactly what files were published as part of this manuscript's data set, and the hash may also be used to check that the data has not changed since publication.

\section{Additional material}

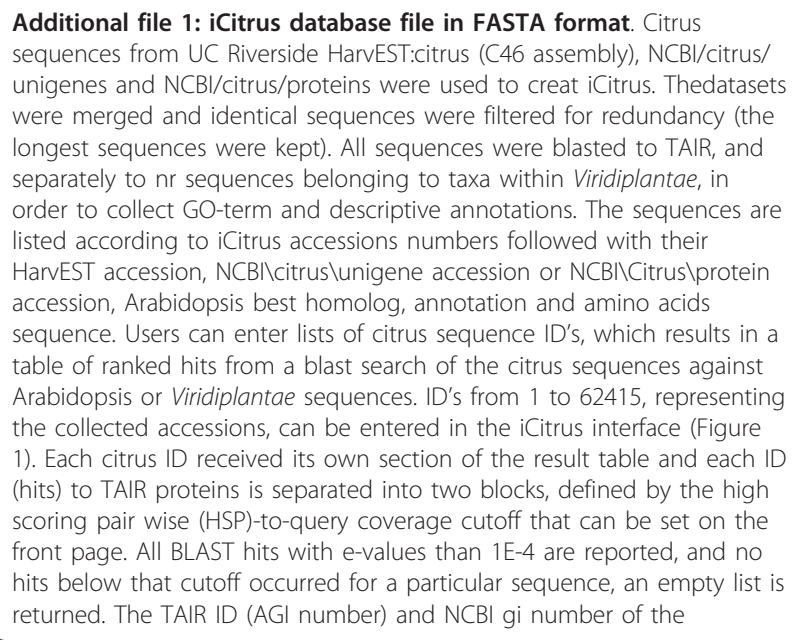


Arabidopsis or Viridiplantae protein similar to the citrus sequence are shown next, including links to TAIR and NCBI. Finally, GO annotations are listed when available. The final column "Annotation" contains TAIRspecific annotations that do not use the same terms as the Gene Ontology, but are available for the TAIR proteins. The data can be downloaded to any spreadsheet.

Additional file 2: Table S1. Conversion table into iCitrus. Conversion table of HarvEST:Citrus, NCBI/Citrus/ESTs and NCBI/Citrus/Proteins accessions into iCitrus accessions. A complete list of all iCitrus accessions can be found in columns A (62,415 accessions). Column A consists of accessions from three databases: (1) NCBI/Citrus/Unigenes (accessions are numbered S\#\#\#\#\#) (2) HarvEST:Citrus ESTs (UC46_\#\#\#\#\#) (3) NCBI/Citrus/ Proteins (\#\#\#\#) and column B consist of the corresponding iCitrus ID's. iCitrus ID's organized in ascending order. A list of accessions, originated from the three databases that were found to be clustered together is shown in columns D-F. Column D consists of accessions that were found to be clustered with other accessions and column $\mathrm{E}$ consists of accessions that clustered with accessions in column D. Column F consists of the corresponding iCitrus accessions of the clustered accessions appeared in columns D and E. A list of accessions that are found in the databases (NCBI and HarvEST:Citrus) but are shorter than 50 AA between stop codons, are shown in column $\mathrm{H}$. These sequences were taken out of iCitrus database and cannot be found in the FASTA file (Additional File 1). Fast conversion table between the different sources of sequences can be found in columns L-O.

Additional file 3: Figure S1. Alignment and analysis of LC-MS/MS runs. 10 replicate LC-MS/MS runs (5 per condition) aligned and analyzed using SIEVE. Several examples for high accuracy RT-XIC pairs are shown. (a) RT-XIC pair for early stage II in blue and stage II, in red. (b) A peptide significantly up-regulated in Blue, (c) a peptide that does not show a significant expression difference, and (d) a peptide significantly upregulated in red.

\section{Acknowledgements}

This work was supported by a research grant No. US-4010-07C from BARD, the United States-Israel Binational Agricultural Research and Development Fund, grant \#5200-117 from the California Citrus Research Board, and by the Will W. Lester Endowment, University of California.

\section{Author details}

'Department of Plant Sciences, University of California, Davis, CA, 95616, USA. ${ }^{2}$ Genome Center, Proteomics Core Facility, University of California, Davis, CA, 95616, USA. ${ }^{3}$ Genome Center, Bioinformatics Core Facility, University of California, Davis, CA 95616, USA. ${ }^{4}$ Department of Fruit Tree Species, ARO, The Volcani Center, 50250 Bet Dagan, Israel.

\section{Authors' contributions}

EK, MGF, AS and EB conceived and designed the experiments. EK, MGF, RAE, and BSP performed the experiments. JNF and DL contributed to the design of iCitrus. EK, MGF, RAE, BSP, AS and EB analyzed the data. EK and EB drafted the manuscript. All authors read and approved the final manuscript.

\section{Competing interests}

The authors declare that they have no competing interests.

Received: 20 October 2010 Accepted: 16 December 2010 Published: 16 December 2010

\section{References}

1. Sarry JE, Sommerer N, Sauvage FX, Bergoin A, Rossignol M, Albagnac G, Romieu C: Grape berry biochemistry revisited upon proteomic analysis of the mesocarp. Proteomics 2004, 4:201-215.

2. Carrari F, Baxter C, Usadel B, Urbanczyk-Wochniak E, Zanor M-I, NunesNesi A, Nikiforova V, Centero D, Ratzka A, Pauly M, et al: Integrated analysis of metabolite and transcript levels reveals the metabolic shifts that underlie tomato fruit development and highlight regulatory aspects of metabolic network behavior. Plant Physiology 2006, 142:1380-1396.
3. Rocco M, D'Ambrosio C, Arena S, Faurobert M, Scaloni A, Marra M: Proteomic analysis of tomato fruits from two ecotypes during ripening. Proteomics 2006, 6:3781-3791.

4. Deluc L, Grimplet J, Wheatley M, Tillett R, Quilici D, Osborne C, Schooley D, Schlauch K, Cushman J, Cramer G: Transcriptomic and metabolite analyses of Cabernet Sauvignon grape berry development. BMC Genomics 2007, 8:429.

5. Faurobert M, Mihr C, Bertin N, Pawlowski T, Negroni L, Sommerer N, Causse M: Major proteome variations associated with cherry tomato pericarp development and ripening. Plant Physiology 2007, 143:1327-1346.

6. Mounet F, Lemaire-Chamley M, Maucourt M, Cabasson C, Giraudel JL, Deborde C, Lessire R, Gallusci P, Bertrand A, Gaudillere M, et al: Quantitative metabolic profiles of tomato flesh and seeds during fruit development: complementary analysis with ANN and PCA. Metabolomics 2007, 3:273-288.

7. Fait A, Hanhineva K, Beleggia R, Dai N, Rogachev I, Nikiforova VJ, Fernie AR, Aharoni A: Reconfiguration of the achene and receptacle metabolic networks during strawberry fruit development. Plant Physiology 2008, 148:730-750.

8. Zanor MI, Rambla J-L, Chaib J, Steppa A, Medina A, Granell A, Fernie AR, Causse M: Metabolic characterization of loci affecting sensory attributes in tomato allows an assessment of the influence of the levels of primary metabolites and volatile organic contents. Journal of Experimental Botany 2009, 60:2139-2154.

9. Bantscheff M, Schirle M, Sweetman G, Rick J, Kuster B: Quantitative mass spectrometry in proteomics: a critical review. Analytical Biochemistry 2007, 389:1017-1031.

10. America AHP, Cordewener JHG: Comparative LC-MS: A landscape of peaks and valleys. Proteomics 2008, 8:731-749.

11. Schulze WX, Usadel B: Quantitation in mass-spectrometry-based proteomics. Annual Review of Plant Biology 2010, 61:491-516.

12. Panchaud A, Affolter M, Moreillon P, Kussmann M: Experimental and computational approaches to quantitative proteomics: Status quo and outlook. Journal of Proteomics 2008, 71:19-33.

13. Ünlü M, Morgan ME, Minden JS: Difference gel electrophoresis. A single gel method for detecting changes in protein extracts. Electrophoresis 1997, 18:2071-2077.

14. Tonge R, Shaw J, Middleton B, Rowlinson R, Rayner S, Young J, Pognan F, Hawkins E, Currie I, Davison M: Validation and development of fluorescence two-dimensional differential gel electrophoresis proteomics technology. Proteomics 2001, 1:377-396.

15. Washburn MP, Wolters $D$, Yates JR: Large-scale analysis of the yeast proteome by multidimensional protein identification technology. Nature Biotechnology 2001, 19:242-247.

16. Washburn MP, Ulaszek R, Deciu C, Schieltz DM, Yates JR: Analysis of quantitative proteomic data generated via multidimensional protein identification technology. Analytical Chemistry 2002, 74:1650-1657.

17. Wu CC, MacCoss MJ, Howell KE, Yates JR: A method for the comprehensive proteomic analysis of membrane proteins. Nature Biotechnology 2003, 21:532-538.

18. Katz E, Fon M, Lee Y, Phinney B, Sadka A, Blumwald E: The citrus fruit proteome: insights into citrus fruit metabolism. Planta 2007, 226:989-1005.

19. Ong S-E, Blagoev B, Kratchmarova I, Kristensen DB, Steen H, Pandey A, Mann M: Stable isotope labeling by amino acids in cell culture, SILAC, as a simple and accurate approach to expression proteomics. Molecular and Cellular Proteomics 2002, 1:376-386.

20. Hansen KC, Schmitt-Ulms G, Chalkley RJ, Hirsch J, Baldwin MA, Burlingame AL: Mass spectrometric analysis of protein mixtures at low levels using cleavable ${ }^{13} \mathrm{C}$-isotope-coded affinity tag and multidimensional chromatography. Molecular and Cellular Proteomics 2003, 2:299-314.

21. Li J, Steen H, Gygi SP: Protein profiling with cleavable isotope-coded affinity tag (cICAT) reagents: The yeast salinity stress response. Molecular and Cellular Proteomics 2003, 2:1198-1204.

22. Ross PL, Huang YN, Marchese JN, Williamson B, Parker K, Hattan S, Khainovski N, Pillai S, Dey S, Daniels S, et al: Multiplexed protein quantitation in saccharomyces cerevisiae using amine-reactive isobaric tagging reagents. Molecular and Cellular Proteomics 2004, 3:1154-1169.

23. Miyagi M, Rao KC: Proteolytic ${ }^{18} \mathrm{O}$-labeling strategies for quantitative proteomics. Mass Spectrometry Reviews 2007, 26:121-136. 
24. Wang M, You J, Bemis KG, Tegeler TJ, Brown DPG: Label-free mass spectrometry-based protein quantification technologies in proteomic analysis. Brief Funct Genomic Proteomic 2008, 7:329-339.

25. Old WM, Meyer-Arendt K, Aveline-Wolf L, Pierce KG, Mendoza A, Sevinsky JR, Resing KA, Ahn NG: Comparison of label-free methods for quantifying human proteins by shotgun proteomics. Molecular and Cellular Proteomics 2005, 4:1487-1502.

26. Stevenson SE, Chu Y, Ozias-Akins P, Thelen JJ: Validation of gel-free, labelfree quantitative proteomics approaches: Applications for seed allergen profiling. Journal of Proteomics 2009, 72:555-566.

27. Bondarenko PV, Chelius D, Shaler TA: Identification and relative quantitation of protein mixtures by enzymatic digestion followed by capillary reversed-phase liquid chromatography-tandem mass spectrometry. Analytical Chemistry 2002, 74:4741-4749.

28. Chelius D, Bondarenko PV: Quantitative profiling of proteins in complex mixtures using liquid chromatography and mass spectrometry. Journal of Proteome Research 2002, 1:317-323.

29. Wang W, Zhou H, Lin H, Roy S, Shaler TA, Hill LR, Norton S, Kumar P, Anderle $\mathrm{M}$, Becker $\mathrm{CH}$ : Quantification of proteins and metabolites by mass spectrometry without isotopic labeling or spiked standards. Analytical Chemistry 2003, 75:4818-4826.

30. Liu H, Sadygov RG, Yates JR: A model for random sampling and estimation of relative protein abundance in shotgun proteomics. Analytical Chemistry 2004, 76:4193-4201.

31. Gilchrist A, Au CE, Hiding J, Bell AW, Fernandez-Rodriguez J, Lesimple S, Nagaya H, Roy L, Gosline SJC, Hallett M: Quantitative proteomics analysis of the secretory pathway. Cell 2006, 127:1265-1281.

32. Wang G, Wu WW, Zeng W, Chou C-L, Shen R-F: Label-free protein quantification using LC-coupled ion trap or FT mass spectrometry: reproducibility, linearity, and application with complex proteomes. Journal of Proteome Research 2006, 5:1214-1223.

33. Baginsky S: Plant proteomics: Concepts, applications, and novel strategies for data interpretation. Mass Spectrometry Reviews 2009, 28:93-120.

34. Bianco L, Lopez L, Scalone AG, Di Carli M, Desiderio A, Benvenuto E, Perrotta G: Strawberry proteome characterization and its regulation during fruit ripening and in different genotypes. Journal of Proteomics 2009, 72:586-607.

35. Shi JX, Chen S, Gollop N, Goren R, Goldschmidt EE, Porat R: Effects of anaerobic stress on the proteome of citrus fruit. Plant Science 2008, 175:478-486.

36. Muccilli V, Licciardello C, Fontanini D, Russo MP, Cunsolo V, Saletti R, Reforgiato Recupero G, Foti S: Proteome analysis of Citrus sinensis L. (Osbeck) flesh at ripening time. Journal of Proteomics 2009, 73:134-152.

37. Tanou G, Job C, Rajjou L, Arc E, Belghazi M, Diamantidis G, Molassiotis A Job D: Proteomics reveals the overlapping roles of hydrogen peroxide and nitric oxide in the acclimation of citrus plants to salinity. The Plant Journal 2009, 60:795-804.

38. Yun Z, Li W, Pan Z, Xu J, Cheng Y, Deng X: Comparative proteomics analysis of differentially accumulated proteins in juice sacs of ponkan (Citrus reticulata) fruit during postharvest cold storage. Postharvest Biology and Technology 2010, 56:189-201.

39. Zhang B, VerBerkmoes NC, Langston MA, Uberbacher E, Hettich RL, Samatova NF: Detecting differential and correlated protein expression in label-free shotgun roteomics. Journal of Proteome Research 2006, 5:2909-2918.

40. Foss EJ, Radulovic D, Shaffer SA, Ruderfer DM, Bedalov A, Goodlett DR, Kruglyak L: Genetic basis of proteome variation in yeast. Nature Genetics 2007, 39:1369-1375.

41. Gstaiger M, Aebersold R: Applying mass spectrometry-based proteomics to genetics, genomics and network biology. Nature Reviews Genetics 2009, 10:617-627.

42. Choudhary C, Mann M: Decoding signalling networks by mass spectrometry-based proteomics. Nature Reviews Molecular Cell Biology 2010, 11:427-439.

43. Zybailov B, Rutschow H, Friso G, Rudella A, Emanuelsson O, Sun Q, van Wijk KJ: Sorting signals, N-terminal modifications and abundance of the chloroplast proteome. PLOS ONE 2008, 3:e1994.

44. Talon M, Gmitter FG: Citrus Genomics. Interbational Journal of Plant Genomics 2008.
45. Ebine $\mathrm{K}$, Ueda T: Unique mechanism of plant endocytic/vacuolar transport pathways. Journal of Plant Research 2009, 122:21-30.

46. Zerial M, McBride H: Rab proteins as membrane organizers. Nature Reviews Molecular Cell Biology 2001, 2:107-117.

47. Nielsen E, Cheung AY, Ueda T: The regulatory RAB and ARF GTPases for vesicular trafficking. Plant Physiology 2008, 147:1516-1526.

48. Vernoud V, Horton AC, Yang Z, Nielsen E: Analysis of the small GTPase gene superfamily of Arabidopsis. Plant Physiology 2003, 131:1191-1208.

49. Winter $V$, Hauser M-T: Exploring the ESCRTing machinery in eukaryotes. Trends in Plant Science 2006, 11:115-123.

50. Smith LG, Oppenheimer DG: Spatial control of cell expansion by the plant cytoskeleton. Annual Review of Cell and Developmental Biology 2005, 21:271-295.

51. Reddy VS, Safadi F, Zielinski RE, Reddy ASN: Interaction of a kinesin-like protein with calmodulin isoforms from Arabidopsis. Journal of Biological Chemistry 1999, 274:31727-31733.

52. McCormack E, Tsai Y-C, Braam J: Handling calcium signaling: Arabidopsis CaMs and CMLs. Trends in Plant Science 2005, 10:383-389.

53. Smertenko AP, Chang H-Y, Sonobe S, Fenyk SI, Weingartner M, Bogre L, Hussey PJ: Control of the AtMAP65-1 interaction with microtubules through the cell cycle. Journal of Cell Science 2006, 119:3227-3237.

54. Smertenko AP, Kaloriti D, Chang H-Y, Fiserova J, Opatrny Z, Hussey PJ: The C-terminal variable region specifies the dynamic properties of Arabidopsis microtubule-associated protein MAP65 isotypes. Plant Cell 2008, 20:3346-3358.

55. Katz E, Lagunes PM, Riov J, Weiss D, Goldschmidt EE: Molecular and physiological evidence suggests the existence of a system II-like pathway of ethylene production in non-climacteric Citrus fruit. Planta 2004, 219:243-252

56. Bain JM: Morphological, anatomical, and physiological changes in the developing fruit of the Valencia orange, Citrus sinensis (L.) Osbeck. Australian Journal of Botany 1958, 6:1-23.

57. Oeljeklaus S, Meyer HE, Warscheid B: Advancements in plant proteomics using quantitative mass spectrometry. Journal of Proteomics 2009, 72:545-554.

58. Choi H, Fermin D, Nesvizhskii Al: Significance analysis of spectral count data in label-free shotgun proteomics. Molecular and Cellular Proteomics 2008, 7:2373-2385.

59. Aleza P, Juarez J, Hernandez M, Pina J, Ollitrault P, Navarro L: Recovery and characterization of a Citrus clementina Hort. ex Tan. 'Clemenules' haploid plant selected to establish the reference whole Citrus genome sequence. BMC Plant Biology 2009, 110.

60. Elias JE, Haas W, Faherty BK, Gygi SP: Comparative evaluation of mass spectrometry platforms used in large-scale proteomics investigations. Nature Methods 2005, 2:667-675.

61. Keller A, Nesvizhskii Al, Kolker E, Aebersold R: Empirical statistical model to estimate the accuracy of peptide identifications made by MS/MS and database search. Analytical Chemistry 2002, 74:5383-5392.

62. Listgarten J, Emili A: Statistical and computational methods for comparative proteomic profiling using liquid chromatography-tandem mass spectrometry. Molecular and Cellular Proteomics 2005, 4:419-434.

63. Qian W-J, Jacobs JM, Liu T, Camp DG, Smith RD: Advances and challenges in liquid chromatography-mass spectrometry-based proteomics profiling for clinical applications. Molecular and Cellular Proteomics 2006, 5:1727-1744

64. Lu P, Vogel C, Wang R, Yao X, Marcotte EM: Absolute protein expression profiling estimates the relative contributions of transcriptional and translational regulation. Nature Biotechnology 2007, 25:117-124.

65. Lu C, Zainal Z, Tucker GA, Lycett GW: Developmental abnormalities and reduced fruit softening in tomato plants expressing an antisense Rab11 GTPase gene. Plant Cell 2001, 13:1819-1833.

66. Abbal P, Pradal M, Muniz L, Sauvage F-X, Chatelet P, Ueda T, Tesniere C: Molecular characterization and expression analysis of the Rab GTPase family in Vitis vinifera reveal the specific expression of a VvRabA protein. Journal of Experimental Botany 2008, 59:2403-2416.

67. Lycett G: The role of Rab GTPases in cell wall metabolism. Journal of Experimental Botany 2008, 59:4061-4074.

68. Bassham DC, Brandizzi F, Otegui MS, Sanderfoot AA: The secretory system of Arabidopsis. The Arabidopsis Book The American Society of Plant Biologists; 2008, 1-29, The Arabidopsis Book]. 
69. Dettmer J, Hong-Hermesdorf A, Stierhof Y-D, Schumacher K: Vacuolar H +-ATPase activity is required for endocytic and secretory trafficking in Arabidopsis. Plant Cell 2006, 18:715-730.

70. Marshansky V, Futai M: The V-type H+-ATPase in vesicular trafficking: targeting, regulation and function. Curr Opin Cell Biol 2008, 20:415-426.

71. Soule J, Grierson W: Anatomy and physiology. In Fresh citrus fruit. Edited by: Wardowski W, Nagy s. W. G: AVl, Westport, Conn; 1986:1-22.

72. Spiegel-Roy P, Goldschmidt EE: Biology of Citrus Cambridge University Press; 1996.

73. Etxeberria E, Gonzalez P, Pozueta J: Evidence for two endocytic transport pathways in plant cells. Plant Science 2009, 177:341-348.

74. Etxeberria E, Gonzalez P, Pozueta-Romero J: Sucrose transport into citrus juice cells: evidence for an endocytic transport system. Journal of the American Society for Horticultural Science 2005, 130:269-274.

75. Wessel D, Fluegge UI: A method for the quantitative recovery of protein in dilute solution in the presence of detergents and lipids. Analytical Biochemistry 1984, 138:141-143.

76. Rosenfeld J, Capdevielle J, Guillemot JC, Ferrara P: In-gel digestion of proteins for internal sequence analysis after one- or two-dimensional gel electrophoresis. Analytical Biochemistry 1992, 203:173-179.

77. Nesvizhskii Al, Keller A, Kolker E, Aebersold R: A statistical model for identifying proteins by tandem mass spectrometry. Analytical Chemistry 2003, 75:4646-4658.

doi:10.1186/1477-5956-8-68

Cite this article as: Katz et al: A label-free differential quantitative mass spectrometry method for the characterization and identification of protein changes during citrus fruit development. Proteome Science 2010 8:68.

\section{Submit your next manuscript to BioMed Central} and take full advantage of:

- Convenient online submission

- Thorough peer review

- No space constraints or color figure charges

- Immediate publication on acceptance

- Inclusion in PubMed, CAS, Scopus and Google Scholar

- Research which is freely available for redistribution

Submit your manuscript at www.biomedcentral.com/submit
Ciomed Central 